\title{
Inmigración irregular y proceso de regularización en Madrid
}

\author{
Gloria LoRA-Tamayo D'OCón
}

\section{INTRODUCCIÓN}

Entre el 10 de junio de 1991 y el 10 de marzo de 1992 tuvo lugar en España la segunda operación excepcional de Regularización de la población extranjera que se hallaba insuficientemente documentada, a la que comúnmente se alude con el termino de «ilegal».

La primera Regularización, llevada a cabo entre el 23 de julio de 1985 y el 31 de marzo de 1986, previa a la puesta en marcha de la Ley Orgánica 7/1985 de 1 de julio sobre los Derechos y Libertades de los Extranjeros en España, no consiguió legalizar la situación más que de una pequeña parte de la población estimada como indocumentada, resultando en definitiva poco eficaz.

El nuevo proceso, encuadrado en la denominada «política activa de inmigración", puesta en marcha por el gobierno a partir del mismo año de 1991, se consideraba un primer paso fundamental para conseguir la promoción e integración del colectivo inmigrante. Con él se trataba de completar la operación de regularización de 1985, además de legalizar la situación de los trabajadores irregulares llegados con posterioridad al país.

El carácter de la Regularización de inmigrantes de 1991 difiere del primer proceso. Se trata de una Regularización eminentemente laboral, realizada en dos fases. La primera y principal tiene lugar entre el 10 de junio y el 12 de diciembre de 1991. Por ella se concedía una tarjeta conjunta de trabajo y residencia a quienes, justificando su estancia en España antes de la puesta en marcha de la Ley Orgánica $7 / 1985$ de 1 de julio o con posterioridad a esa fecha pero antes del 15 de mayo de 1991, pudieran acreditar una actividad lucrativa continuada, contasen con una oferta firme de empleo regular o estable, formulada por un empresario 
responsable, o quienes tuvieran un proyecto viable de actividad por cuenta propia.

La segunda fase, cuyo plazo se cerraba el 10 de marzo de 1992, constituía una Regularización de Familiares, a la que sólo tenian acceso los familiares directos de los trabajadores recientemente regularizados, que se hallaran en España antes del 15 de mayo de 1991, residiendo en situación irregular. Si su solicitud era fallada favorablemente, accedían a la tarjeta de residencia.

El número total de solicitudes presentadas y admitidas a trámite al proceso de Regularización de Trabajadores fue de 135.393 para el conjunto de España (R. Aragón y J. Chozas, 1993), de las que se anularon un 1\% por estar duplicadas o tener los solicitantes permiso en vigor. De las restantes, 5.501 se archivaron por pertenecer a ciudadanos comunitarios, quienes a partir del 1 de enero de 1992 quedaban exentos de la obligación de obtener permiso de trabajo ${ }^{1}$. A 31 de diciembre de 1993, fecha para la que contamos con los últimos datos estadísticos del proceso, han sido resueltas 128.128 solicitudes, que han supuesto 110.113 permisos concedidos y 18.015 denegados.

En cuanto a la Regularización de Familiares, el total de solicitudes presentadas fue de 6.777 para toda España - un volumen considerado como muy reducido-. De ellas, únicamente han sido denegadas 104 , resolviéndose favorablemente 5.889 y constituyendo expedientes pendientes 784 , que han pasado a resolverse por Régimen General.

Los resultados del proceso de Regularización de Trabajadores son publicados periódicamente a través de «Informes Estadísticos de Regularización», por la Dirección General de Migraciones. Tanto la población que ha obtenido permiso, como la que ha visto denegada su solicitud, así como la que ha acudido a la renovación, aparece clasificada en los informes por sexo, estado civil, clase de permiso, nacionalidad, distribución por provincias, distribución por C.N.O. y C.N.A.E. y edad.

De la Regularización de Familiares, realizada a través de la Dirección General de Policia, no se publican estadisticas, por lo que su análisis en profundidad es difícil.

\footnotetext{
Con anterioridad a esa fecha se habian resuelto 2.536 expedientes de nacionales comunitarios, que quedan incluidos en las cifras de solicitudes resueltas favorablemente (R.ARAGON BOMBIN Y J.CHOzAS PEDRERO, 1993).
} 
Sin embargo, los informes de la Dirección General de Migraciones y la base de datos de la que emanan son fuente valiosísima para la investigación de la mayor parte del colectivo inmigrante irregular en España, población cuyo volumen y características se conocía sólo a través de estimaciones y deducciones a partir de grupos aislados o relacionados con instituciones y Ongs.

Madrid constituye un punto de destino fundamental en lo que a la inmigración extranjera se refiere. Del Informe Estadístico de Regularización a 31 de diciembre de 1993 se deduce que el $31 \%$ de las solicitudes resueltas en el conjunto de España correspondieron a Madrid. La provincia se halla a la cabeza de la inmigración de trabajadores en situación irregular del país, seguida de Barcelona, que acaparaba el $23 \%$ de los irregulares. Las restantes provincias tenían una menor relevancia, a pesar de ser algunas de ellas focos importantes de inmigración regular.

En estas páginas se analizan los datos referidos a la Regularización de trabajadores extranjeros en la Comunidad de Madrid, extraídos del «Fichero de Regularización del proceso inicial" correspondiente a Madrid, a 1 de diciembre de 1993, facilitado por la Dirección General de Migraciones y explotado y elaborado personalmente. Consideramos esta fuente fundamental para el estudio de la población inmigrante extranjera en situación irregular en la Comunidad.

\section{INMIGRACIÓN IRREGULAR Y PROCESO DE REGULACIÓN EN MADRID}

Madrid se ha venido considerando en los últimos años, junto con Barcelona, como el foco más importante de inmigración irregular de España. Las estimaciones de ilegales en la provincia llegaron a apuntar hasta 100.000 personas en la segunda mitad de la década de los 80 (loé, 1987; C. Pereda, 1987). Otras estimaciones más modestas situaban la cifra entre 40.000 y 80.000 irregulares: el grupo de trabajo PASS (1990) calculaba en 65.121 la población inmigrante atendida por organizaciones no gubernamentales de ayuda, servicios sociales municipales y autonómicos, instituciones, organismos oficiales y expertos cualificados. Este "mínimo de observación directa», referido a 1989 , supondría el $25 \%$ del calculado para España por el mismo equipo. Sobre esa cifra, PASS calculaba una segunda para la misma fecha como "estimación fiable», resultado de la agregación de otros datos estimativos aportados por algunas organizaciones o informantes cualificados: 82.000 personas, que 
supondrian el $31,6 \%$ de los inmigrantes irregulares estimados en el conjunto de España ${ }^{2}$.

El diario "El Sol» difundía el 13 de marzo de 1991 la cifra de 40.000 inmigrantes ilegales en Madrid en los primeros meses del año. La estimación, muy por debajo de las anteriores, procedía de la Consejería de Integración Social de la CAM y se basaba, al parecer, en un estudio realizado o encargado por la propia Consejería. El trabajo llevado a cabo para este organismo por un numero de investigadores, coordinado por $\mathrm{C}$. Giménez y denominado "Dimensionamiento y análisis por grupos étnicos de la población inmigrante del tercer mundo y Portugal en la Comunidad Autónoma de Madrid", al que podría hacer referencia la noticia periodística, no ofrece, sin embargo, estimaciones globales del número de inmigrantes irregulares en la CAM.

No obstante, la cifra divulgada por aquel diario es la más próxima a la de la población en situación irregular que acudió al proceso excepcional de Regularización de trabajadores en Madrid: 39.560 personas, según el Informe Estadístico elaborado por la Dirección General de Migraciones a 31 de diciembre de 1993. La cifra supone el $30,9 \%$ de la población que acudió al proceso en España. A ella habría que añadir la de los expedientes archivados de ciudadanos comunitarios correspondientes a Madrid - cuyo número podría rondar los $2.200^{3}$-, además de los familiares de trabajadores extranjeros que se acogieron en Madrid al proceso paralelo: 2.141 personas, que supusieron el $31,6 \%$ de la población que acudió a la Regularización de familiares, cifra sólo superada por Barcelona que con 2.604 personas concentró el $38,4 \%$ del conjunto nacional.

En total, la población extranjera que acudió en Madrid al doble proceso de Regularización, alcanzó una cifra próxima a las 44.000 personas. Este volumen es muy superior al de los expedientes resueltos en la operación de $1985-86$, que en numero de 5.121 supusieron el $13,4 \%$ del conjunto nacional, figurando Madrid, en esta ocasión, por debajo de Barcelona.

También debe contrastarse la cifra de los extranjeros que acudieron al proceso del 91 con la de extranjeros que poseían tarjeta de residencia en

\footnotetext{
2 Sobre las estimaciones de población inmigrante indocumentada o en situación irregular en España, véase G.Lora-TAMAYo, 1994.

3 Si extrapolamos el dato de la participación de Madrid en el conjunto nacional de los expedientes de ciudadanos comunitarios que se resolvieron antes del 31 de diciembre de 1991 y que están incluidos en las estadisticas: 2.517 , de los que 1.003 se concentran en Madrid.
} 
el momento -60.904 (?) a 31 de diciembre de $1990^{4}$ - o los que se inscribieron en los Censos de Población y Viviendas de 1991, en número coincidente con el anterior -60.163 personas- ${ }^{5}$.

El volumen de trabajadores en situación irregular que solicitaron sus permisos en la operación excepcional es muy superior al de los extranjeros que se hallaban trabajando legalmente en el momento en Madrid: en diciembre de 1990, 23.668 extranjeros de nacionalidad tenían permiso de trabajo en nuestra comunidad (D.G.M., 1993). La cifra coincide con la de los extranjeros "ocupados" que se inscribieron en el Censo de Población de 1991 (referido a 1 de marzo de ese año) - 23.116-. Los irregulares o “ilegales" vienen casi a duplicar el número de trabajadores legales en Madrid.

La relación entre los que acudieron a la Regularización de 1991 y el total de ilegales residiendo en esa fecha en Madrid, es desconocida. En medios oficiales se considera que el proceso fue eficaz en la erradicación de la bolsa de irregularidad. Sin embargo, es posible que un volumen indeterminado no acudiera al mismo por no reunir los requisitos exigidos, por desconocimiento o incluso por miedo, a pesar de haberse intentado en

4 Si bien esta cifra es poco fiable, debido a los errores contenidos en la Estadistica de Extranjeros Residentes, elaborada por la Dirección General de Policia. El Anuario de Migraciones de 1992, de la Dirección General de Migraciones, que recoge los datos de esta estadística, da la cifra de 60.904 extranjeros residentes en Madrid a 31 de diciembre de 1990, para un total de extranjeros residentes en España de 407.671 en la misma fecha. Como se sabe, la Dirección General de Policia realizó con posterioridad una depuración de los ficheros, ante la existencia en los mismos de un elevado número de tarjetas de residencia caducadas, que hinchaban las cifras de forma importante. El resultado de la corrección es, como sabemos, la rectificación de la cifra global de extranjeros residentes en España a 31 de diciembre de 1990, a 276.796 personas. El Anuario de Migraciones de la D.G.M. de 1993 recoge esa corrección de nivel nacional y rectifica el volumen de extranjeros en Madrid a 62.742, es decir, 2.000 personas más, lo cual no deja de ser curioso y no concuerda con la enorme reducción de la cifra del total nacional. Obviamente, si la primera cifra dada para Madrid no era válida, ésta lo es aún menos, ya que se calculó extrapolando la distribución provincial de los extranjeros con tarjeta de residencia a 31 de diciembre de 1991 , fecha en la que en las estadísticas oficiales se incluia ya un volumen considerable de extranjeros regularizados en la reciente operación, donde Madrid ocupó un lugar muy destacado, distorsionando de esta manera los datos al alza. El Anuario de Migraciones del último año (1994), da la cifra de 60.902 extranjeros residentes en Madrid en diciembre de 1990, recogiendo para ese año la primitiva y errónea cifra de extranjeros residentes en España de 407.647. Desconocemos las causas de estas variaciones por parte de la D.G.M., que muestra en este aspecto ser una fuente poco fiable. Lo que si parece claro es que el número de extranjeros con tarjeta de residencia en Madrid en esa fecha era inferior a los 60.000 .

5 La explotación de los Censos de Población y Viviendas de 1991 por parte de la CAM, arroja una cifra de 60.163 extranjeros. La explotación de los mismos por parte del I.N.E. da como cifra definitiva 61.191 extranjeros de nacionalidad en España en la fecha de referencia. No debe tomarse en consideración la primera cifra publicada por este organismo en la Muestra Avance (1992), de 53.023 personas. 
todo momento que el proceso fuera "creíble» y de la ayuda de los sindicatos y las Ongs en ese sentido.

En este trabajo no se hace equivaler el número de ilegales en el momento de apertura del proceso, al de inmigrantes que acudieron a la Regularización. Consideramos, sin embargo, que la Estadística de Regularización recoge al mayor volumen de extranjeros en situación irregular conocido directamente hasta el momento. En ese sentido es una fuente muy valiosa ${ }^{6}$.

\section{EL FICHERO DE REGULARIZACIÓN DE MADRID}

La fuente que vamos a explotar en este trabajo ha sido facilitada por la Dirección General de Migraciones. En ella figuran las personas que acudieron al proceso de Regularización de trabajadores en Madrid -excluidos los expedientes archivados-, clasificadas por sexo, edad, estado civil, nacionalidad, país de nacimiento, municipio de residencia, clase de permiso, ocupación y actividad económica.

No contamos a este nivel de pormenorización con datos sobre los extranjeros que acudieron al proceso de Regularización de familiares. Su reducido volumen disculpa de alguna manera esta omisión.

Las variables antes señaladas, a excepción del municipio de residencia, referidas no sólo a Madrid, sino a cualquier provincia, pueden ser objeto de información estadística por parte de la Dirección General de Migraciones, al hallarse codificadas en la base de datos. Hasta ahora, sin embargo, este organismo no ha podido facilitar información sobre la distribución espacial a nivel municipal, variable de interés singular para el estudio de las pautas de localización de los inmigrantes irregulares y su comparación con las de los extranjeros que se inscribieron en el último Censo de Población y que en su mayoría debía ser población en situación regular.

La razón está en que los datos referidos a la localidad de residencia de los solicitantes no fueron codificados inicialmente por este organismo, sino

\footnotetext{
- Al proceso acudió un número de solicitantes de asilo o refugio, en situación regular, instados por el propio gobierno a ello, dadas las dificultades de acceso a una situación regular mediante la concesión del estatuto de refugiado o la carta de asilo. En torno al $95 \%$ de los solicitantes no ven fallada favorablemente su solicitud, pasando a engrosar las filas de los ilegales. Asi pues, no todos los incluidos en el fichero eran en el momento inmigrantes ilegales, aunque sí la gran mayoría. Por otra parte, resulta claro que no todos los ilegales acudieron al proceso. Sobre todo ello, véase G. LoRA-TAMaYo, 1994.
} 
que figuran en el Fichero de Regularización en un campo literal, por lo que su explotación es prácticamente imposible: tienen un margen de error tal que los resultados estarian despojados de todo rigor.

Ante la importancia de la variable para el análisis del colectivo inmigrante irregular, se decidió realizar una codificación personal del campo literal de municipio de residencia, sobre el Fichero inicial, para proceder posteriormente a su explotación. El proceso, llevado a cabo por personal cualificado ?, resultó complejo dado el importante volumen de errores de transcripción y la frecuencia de la inclusión de calles o nombres de urbanizaciones en lugar del nombre del municipio. En unos pocos casos hubieron de excluirse registros de personas cuyo municipio de residencia correspondía a otra provincia.

Por último, se completó la puesta a punto del Fichero mediante un trabajo de recodificación, agrupando los municipios en áreas y corredores, y los países de origen en espacios geográficos de mayor amplitud, para hacer los datos comparables con las clasificaciones utilizadas por la CAM.

Como consecuencia del proceso llevado a cabo, los 39.557 registros iniciales del Fichero actualizado a 1 de diciembre de 1993, que incluye las solicitudes tramitadas correspondientes, tanto a los permisos denegados como a los concedidos, han quedado reducidos en el fichero final a 39.484, existiendo por tanto una pérdida de 73 casos tras los procesos de codificación y recodificación seguidos. Esta pérdida, inferior al 0,2\% de la información inicial es admisible y no desvirtúa en absoluto los resultados finales.

Antes de iniciar la explotación del fichero, conviene señalar la imposibilidad de analizar la distribución espacial de los inmigrantes irregulares en el interior de la capital, tema de indudable interés. Esta información no fue objeto de informatización, por lo que no aparece en el Fichero inicial, aunque sí en las solicitudes rellenadas por los inmigrantes.

\section{CARACTERISTICAS DE LA POBLACIÓN QUE ACUDIÓ AL PROCESO DE REGULARIZACIÓN DE TRABAJADORES}

Al analizar el colectivo que acudió al proceso excepcional de Regularización de trabajadores, como exponente de la inmigración irregular en la Comunidad de Madrid, conviene tener en cuenta las siguientes consideraciones:

\footnotetext{
7 La persona encargada del trabajo de codificación y puesta a punto del Fichero inicial fue Ignacio Estevez, Estadístico Técnico del INE, que llevó a cabo el proceso con absoluta eficacia. Desde aqui nuestro reconocimiento a su labor.
} 
Incluimos a la totalidad de los solicitantes registrados en el fichero. De ellos, sabemos que un $90,5 \%$ son población efectivamente regularizada y un $9,5 \%$ son personas a quienes se denegó su solicitud ${ }^{8}$. Al hallarse recurridos muchos de los expedientes denegados, existen modificaciones en el valor de las concesiones - su número tiende a incrementarse- y las denegaciones - que tienden a disminuir-, con posterioridad a la fecha puntual a la que hacen referencia los datos que se presentan. Los datos se analizarán de forma conjunta, sin distinguir concesiones de denegaciones, no sólo para agilizar la exposición, sino, sobre todo, porque el objetivo de este trabajo es conocer las características del conjunto de la población extranjera irregular.

El fichero contiene sólo población activa, solicitante del permiso conjunto de Residencia y Trabajo. Algunas variables como el sexo o, sobre todo, la edad, están marcadas por este hecho. No encontramos población menor de 16 años. Ratios como la tasa de actividad o la de dependencia, no pueden obviamente ser analizadas. Recordemos que la población inactiva dependiente de los regularizados podía acudir al proceso de Regularización de Familiares, al que sin embargo se presentó un reducido número de personas, que no quedan incluidas en este estudio.

La información corresponde al 1 de diciembre de 1993. Para compararla con la de España, tomamos el informe estadístico de Regularización más próximo en el tiempo, correspondiente al 30 de noviembre de 1993, a pesar de que existe un informe posterior. Las variaciones en las estadísticas son mínimas.

\subsection{Continente y país de nacionalidad}

En Madrid, la población extranjera en situación irregular tenía un origen continental más diversificado que en España. El predominio de la población africana en el conjunto nacional se repite, aunque con una intensidad más moderada (cf. fig. 1). En contraposición, el peso de la población centro y sudamericana y del resto de Europa es mayor en la comunidad que nos ocupa.

Madrid concentra el $31 \%$ de la población extranjera trabajadora que acudió a la Regularización de 1991 en España. El porcentaje de participación

8 El número de permisos conjuntos de trabajo y residencia concedidos a inmigrantes por via de la operación de Regularización, era a 1 de diciembre de 1993 de 35.810 , lo que suponia el $90,5 \%$ del total de solicitudes; se denegaron 3.747 , el $9,5 \%$. Las proporciones de concesiones y denegaciones en toda España en la operación fueron, respectivamente, $85,9 \%$ y $14,1 \%$. 


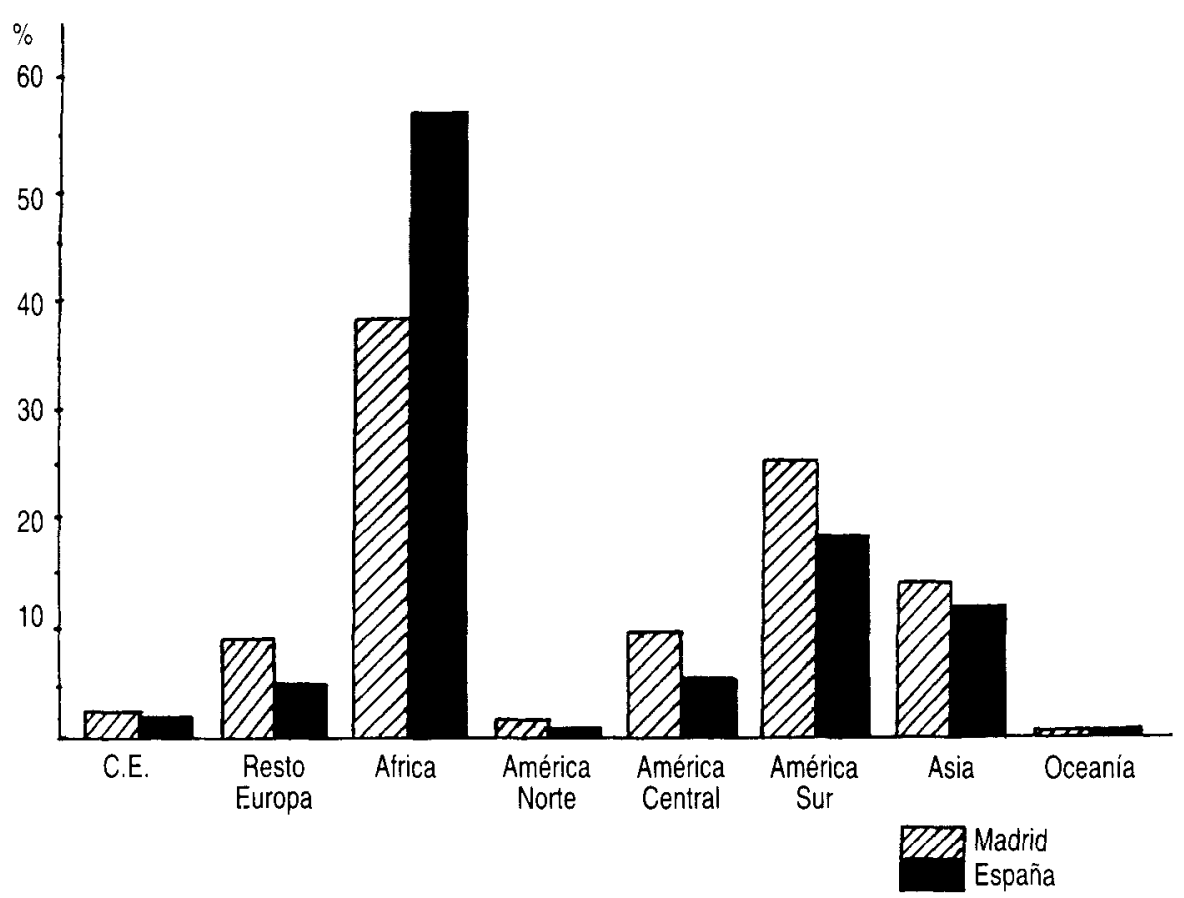

Fuente: D.G.M. Elaboración Propia.

Figura 1. Continente de nacionalidad de los trabajadores extranjeros en situación irregular en Madrid y España. 1991.

de la comunidad en el contexto nacional, sin embargo, varia según las colonias. De mayor a menor peso: Madrid concentra el $61 \%$ de los nacionales de la Europa no comunitaria que acudieron a la Regularización; el 55\% de los nacionales de Centroamérica; el $44 \%$ de los norteamericanos; el $42 \%$ de los sudamericanos; el $40 \%$ de los comunitarios; el $37 \%$ de los asiáticos; el 36\% de los nacionales de Oceanía; sólo el 21 de los africanos, y, por último, el $6 \%$ de los apátridas.

Con todo, Africa es el continente de nacionalidad más importante de la población trabajadora extranjera en situación irregular en Madrid. Dentro del mismo, el país de mayor presencia era Marruecos, de donde eran nacionales el $79 \%$ de los africanos. Le seguían, a gran distancia, Guinea Ecuatorial, Cabo Verde, Senegal, Nigeria y Angola, por este orden, con un peso, en todos los casos, inferior al $4 \%$. Entre los sudamericanos destaca 
la representación de Perú, que supone más de un tercio de la colonia, seguida de Argentina (casi una cuarta parte), Colombia (12\%) y Chile $(10,5 \%)$. El $87 \%$ de los centroamericanos en situación irregular son nacionales de la República Dominicana; el $63 \%$ de los comunitarios, portugueses y el $72 \%$ de los procedentes de la Europa extracomunitaria, polacos. En cuanto a la población de origen asiático, casi dos terceras partes son nacionales de China y un $19 \%$ de Filipinas.

Como ocurre en el caso de España (G.Lora-Tamayo, 1994 y 1995 a y b), la distribución de la población extranjera irregular por continente de nacionalidad en Madrid, difiere de la que muestra la población que se inscribió en el Censo de 1991 y que se puede considerar mayoritariamente regular (cf. cuadro 1 y fig. 2).

\section{CUADRO 1. CONTINENTE DE NACIONALIDAD DE LA POBLACIÓN EXTRANJERA IRREGULAR Y CENSADA (1991) EN MADRID.}

\begin{tabular}{|c|c|c|c|c|}
\hline & \multicolumn{2}{|c|}{ EXTRANJEROS IRREGULARES } & \multicolumn{2}{|c|}{ EXTRANJEROS CENSADOS } \\
\hline & C.A. & $\%$ & C.A. & $\%$ \\
\hline Europa.......................... & 4.766 & 12,0 & 21.040 & 35,0 \\
\hline Africa $\ldots \ldots \ldots \ldots \ldots \ldots \ldots \ldots \ldots \ldots \ldots \ldots \ldots \ldots$ & 14.994 & 38,0 & 7.392 & 12,3 \\
\hline América Norte ................ & 796 & 2,0 & 7.675 & 12,7 \\
\hline América Centro ............... & 3.724 & 9,4 & 3.389 & 5,6 \\
\hline América Sur.................... & 9.737 & 24,7 & 13.771 & 22,9 \\
\hline 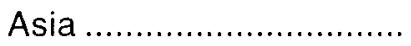 & 5.361 & 13,6 & 6.417 & 10,7 \\
\hline Oceanía ......................... & 35 & 0,1 & 163 & 0,3 \\
\hline Apátridas ..................... & 48 & 0,0 & - & - \\
\hline 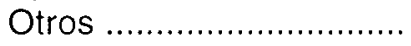 & 87 & 0,2 & 316 & 0,5 \\
\hline No consta ....................... & 23 & 0,1 & - & - \\
\hline TOTAL $\ldots \ldots \ldots \ldots \ldots \ldots \ldots \ldots$ & 39.484 & 100,0 & 60.163 & 100,0 \\
\hline
\end{tabular}

Fuente: D.G.M., C.A.M. Elaboración propia.

Hemos de recordar que el Censo de 1991 hace referencia a la población que se hallaba en nuestro país el 1 de marzo de ese año. Es una fuente sincrónica a la Estadistica de Regularización. La inscripción en el Censo no es obligatoria, por lo que, en el caso de la población extranjera, se piensa que la mayor parte de las personas que se hallaban en situación irregular no se inscribirían, por temor a ser "descubiertas". La confrontación de distintas estadísticas corrobora esta hipótesis (G.Lora-Tamayo, 1995 b). Se puede considerar, en general, a los extranjeros censados como población "asentada», frente a los irregulares, cuya situación es 


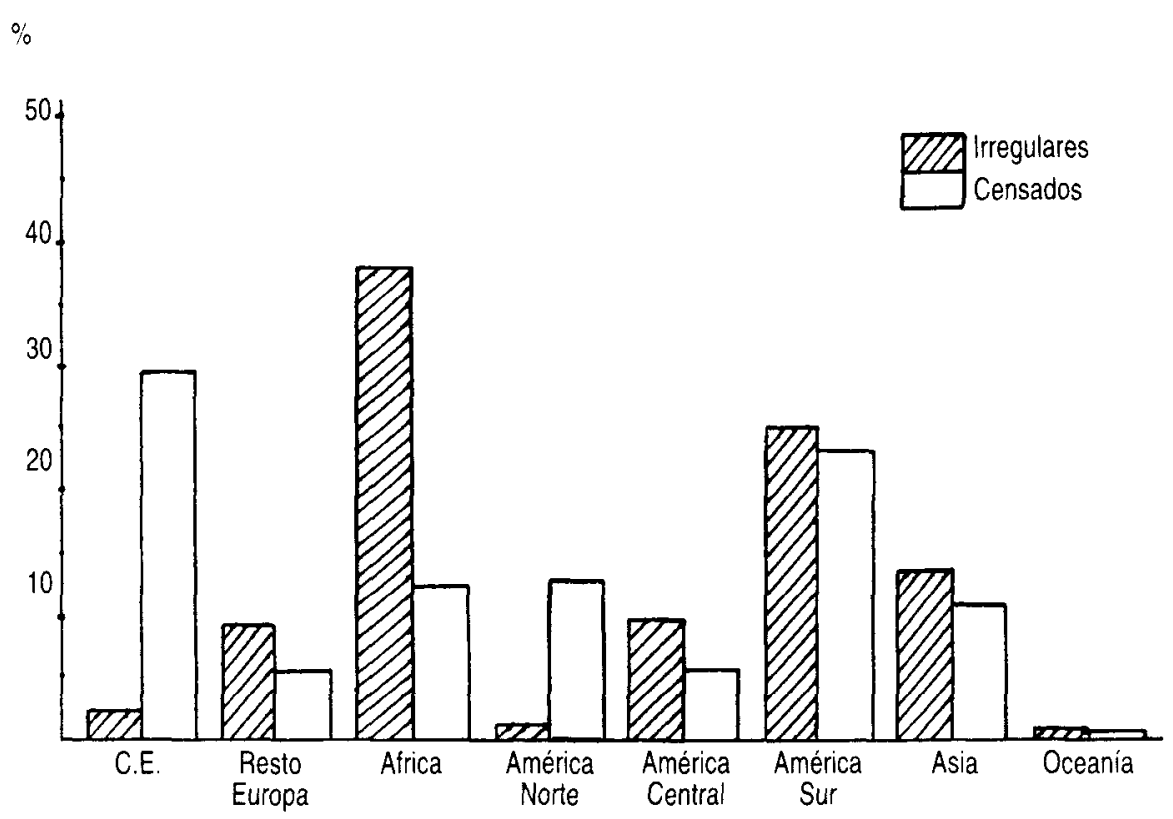

Fuente: D.G.M. y C.A.M. Elaboración Propia.

Figura 2. Continente de nacionalidad de los trabajadores extranjeros en situación irregular y de la población extranjera censada. Madrid. 1991.

menos estable. Se trata de dos fuentes coincidentes en el tiempo y paralelas, aunque existen indudablemente solapamientos entre ellas.

Los contrastes mayores en la distribución por continente de nacionalidad entre "asentados" e irregulares están en el gran peso del continente europeo y norteamericano - el primer mundo- en los primeros y su pequeña representación entre los irregulares, donde destaca el origen africano. Las cifras absolutas son significativas: frente a 7.392 africanos censados, existen 14.994 irregulares en el mismo momento en Madrid. También el número de centroamericanos censados es algo inferior al de irregulares; en el caso de los asiáticos las cifras son parecidas.

Descendiendo de escala, más de tres cuartas partes de los trabajadores irregulares de Madrid, eran nacionales de sólo diez paises, todos ellos pertenecientes al mundo subdesarrollado o en vías de desarrollo (cf. cuadro 2). 
CUADRO 2. PAIIS DE NACIONALIDAD DE LOS TRABAJADORES EXTRANJEROS EN SITUACIÓN IRREGULAR. MADRID/ESPAÑA (1991).

\begin{tabular}{|c|c|c|c|c|}
\hline & \multicolumn{2}{|c|}{ MADRID } & \multicolumn{2}{|c|}{ ESPAÑA } \\
\hline & C.A. & $\%$ & C.A. & $\%$ \\
\hline 1. Marruecos.................. & 11.828 & 30,0 & 56.434 & 44,0 \\
\hline 2. Perú........................ & 3.476 & 8,8 & 5.910 & 4,6 \\
\hline 3. China ......................... & 3.371 & 8,5 & 6.982 & 5,4 \\
\hline 4. R. Dominicana ......... & 3.259 & 8,3 & 5.794 & 4,5 \\
\hline 5. Polonia ..................... & 2.630 & 6,7 & 3.459 & 2,7 \\
\hline 6. Argentina .................. & 2.302 & 5,8 & 7.733 & 6,0 \\
\hline 7. Colombia ................ & 1.209 & 3,1 & 2.323 & 1,8 \\
\hline 8. Filipinas .................... & 1.045 & 2,6 & 2.694 & 2,1 \\
\hline 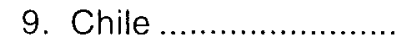 & 1.023 & 2,6 & 2.444 & 1,9 \\
\hline 10. Portugal ..................... & 696 & 1,8 & 1.181 & 0,9 \\
\hline TOTAL, diez primeros .... & 30.839 & 78,2 & 94.954 & 74,1 \\
\hline
\end{tabular}

Fuente: D.G.M. Explotación y elaboración propias.

El primer país de inmigración irregular en Madrid, como en España, es Marruecos, aunque su peso en el conjunto de las colonias de inmigración es inferior en la comunidad que nos ocupa que en el conjunto nacional. Las causas del enorme protagonismo de Marruecos son bien conocidas: la proximidad y fácil acceso hasta enero de 1992, en que se impuso la exigencia de visado, y el contraste en el nivel de desarrollo justifican sobradamente esta presencia. Las trabas y dificultades impuestas por la Ley de Extranjería para legalizar su situación a los ciudadanos sin recursos propios, son la razón fundamental, por otra parte, de la procedencia básicamente tercermundista de la inmigración irregular.

Las colonias de inmigración mas importantes son bastante coincidentes en Madrid y España, si bien en el conjunto nacional tienen menor importancia algunas colonias latinoamericanas, frente a otras procedentes del Africa subsahariana o del Magreb. Así, en España, entre las diez primeras figuran Senegal (4.649) y Argelia (3.739 personas), paises menos representados en Madrid. En contraposición, es de destacar la menor incidencia de la inmigración irregular portuguesa en España que en Madrid; hay que tener en cuenta, en este sentido, que Madrid es un destino relativamente reciente para la emigración portuguesa, de larga tradición en las provincias fronterizas andaluzas, extremeñas y gallegas y en León, fundamentalmente, lugares en los que constituye colonias bastante asentadas (L. López Trigal, 1994). Con todo, las cifras reales de portugueses 
en situación irregular en Madrid y España son con seguridad superiores a las aqui expuestas, si contamos con las correspondientes a portugueses entre los expedientes de ciudadanos comunitarios archivados.

Madrid, como se deduce del cuadro anterior, es provincia de acogida preferente dentro de España para algunas colonias. Así, acoge al $76 \%$ de los trabajadores polacos en situación irregular; al $59 \%$ de los portugueses e igual proporción de los peruanos; $56 \%$ de los dominicanos; $52 \%$ de los colombianos; $48 \%$ de los chinos, $42 \%$ de los chilenos, etc.

Como se sabe, existen ciertos contrastes entre los paises de nacionalidad de la población extranjera "asentada" y la irregular (cf. cuadro 3). Las colonias más importantes de inmigración irregular tienen, por lo general, una buena proporción de población asentada. Así las colonias marroqui o argentina, cuya presencia en España y Madrid es antigua. Las nacionalidades comunitarias, de fuerte presencia entre los extranjeros asentados, tienen poca representación irregular, si exceptuamos la colonia portuguesa, cuyas características difieren notablemente de las del conjunto de los paises de la Unión Europea.

CUADRO 3. PAÍS DE NACIONALIDAD DE LA POBLACIÓN EXTRANJERA CENSADA E IRREGULAR (1991), EN MADRID.

\begin{tabular}{|c|c|c|c|c|}
\hline & \multicolumn{2}{|c|}{ P. CENSADA } & \multicolumn{2}{|c|}{ P. IRREGULAR } \\
\hline & C.A. & $\%$ & C.A. & $\%$ \\
\hline 1. EEUU ....................... & 6.370 & 10,6 & 528 & 1,3 \\
\hline 2. Argentina ................... & 5.032 & 8,4 & 2.302 & 5,8 \\
\hline 3. Marruecos.................. & 4.924 & 8,2 & 11.828 & 30,0 \\
\hline 4. Francia ..................... & 3.792 & 6,3 & 61 & 0,2 \\
\hline 5. Alemania ................... & 3.488 & 5,8 & 45 & 0,1 \\
\hline 6. Portugal .................... & 3.483 & 5,8 & 696 & 1,8 \\
\hline 7. Reino Unido............... & 3.050 & 5,1 & 158 & 0,4 \\
\hline 8. Italia .......................... & 2.255 & 3,7 & 96 & 0,2 \\
\hline 9. Filipinas ................... & 2.083 & 3,5 & 1.045 & 2,6 \\
\hline 10. Perú .......................... & 2.015 & 3,3 & 3.476 & 8,8 \\
\hline 11. Colombia ................... & 1.749 & 2,9 & 1.209 & 3,1 \\
\hline 12. Chile ........................ & 1.719 & 2,9 & 1.023 & 2,6 \\
\hline 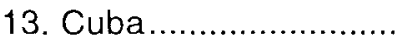 & 1.368 & 2,3 & 139 & 0,4 \\
\hline 14. Venezuela ............... & 1.187 & 2,0 & 182 & 0,5 \\
\hline 15. R. Dominicana.......... & 1.176 & 2,0 & 3.258 & 8,3 \\
\hline 16. Méjico ....................... & 1.093 & 1,8 & 217 & 0,5 \\
\hline TOTAL...... & & 75,0 & & 66,5 \\
\hline
\end{tabular}

Fuente: C.A.M. y D.G.M. Elaboración propia. 
En conclusión, la procedencia de la población extranjera en situación irregular en Madrid, es, como se suponía, básicamente tercermundista, en contraposición con la que se halla en situación regular o con los extranjeros que podríamos denominar «asentados». En relación con el conjunto de irregulares de España, la presencia africana en Madrid es menos significativa, resaltando, en cambio, la población latinoamericana. Algunas colonias nacionales típicas de inmigración económica, como la dominicana, portuguesa o polaca, tienen una importante representación en Madrid.

\subsection{Características demográficas: Sexo y Edad}

La característica fundamental de los extranjeros irregulares es su perfil masculino: el contraste con los que se inscribieron en el último Censo de población es nítido. Mientras entre los irregulares de Madrid son varones el $61 \%$, entre la población censada lo son el $48 \%$. Mayor aún es el contraste en España: eran varones sólo el $49 \%$ de los censados, frente al $74 \%$ de los irregulares. El carácter activo de los irregulares explica el hecho. Por otra parte, el peso entre ellos de colonias eminentemente masculinas, como la africana a nivel global, la polaca o la china, contribuyen a aumentar el valor de los hombres en el conjunto.

Los datos expuestos reflejan un mayor equilibrio de sexos entre la población irregular de Madrid en relación con la de España: tres cuartas partes del colectivo ilegal en nuestro país son hombres y sólo un $24 \%$ mujeres. En Madrid, aun existiendo un desequilibrio del mismo signo, las mujeres en situación irregular ascienden al 39\%. La causa es la mayor representación de la población procedente del continente africano en España que en Madrid, al tiempo que en nuestra comunidad tienen más significación colonias como la sudamericana - de composición bastante equilibrada - o la centroamericana, fundamentalmente femenina. Otros factores, como el tipo de empleo de una parte de los extranjeros en situación irregular en Madrid, el servicio doméstico, de carácter sobre todo femenino, inciden indudablemente en la distribución diferencial de sexos. En este sentido, el índice de masculinidad de los irregulares es prácticamente idéntico al de la población extranjera activa que se inscribió en el Censo, como veremos más adelante.

Como ya se apuntó, la sex ratio es distinta a nivel continental (cf. cuadro 4): las colonias norteamericana y sudamericana, los nacionales de Oceanía y la población comunitaria muestran un equilibrio entre los sexos. Las colonias europea extracomunitaria, africana y asiática, por su parte, son masculinas; el peso de los polacos en la primera y de los chinos en la 
segunda, explican en parte el hecho. Por último, la colonia centroamericana - básicamente dominicana- es la que más desequilibrio muestra y en este caso de signo contrario: es mayoritariamente femenina.

CUADRO 4. EXTRANJEROS EN SITUACIÓN IRREGULAR EN MADRID, SEGÚN SEXO, POR CONTINENTE DE NACIONALIDAD.

\begin{tabular}{|c|c|c|c|c|c|c|}
\hline & \multicolumn{2}{|c|}{ HOMBRES } & \multicolumn{2}{|c|}{ MUJERES } & \multicolumn{2}{|c|}{ TOTAL } \\
\hline & C.A. & $\%$ & $\mathrm{CA}$. & $\%$ & C.A. & $\%$ \\
\hline Unión Europea....... & 525 & 52,3 & 478 & 47,7 & 1.003 & 100,0 \\
\hline Resto Europa........ & 2.755 & 75,5 & 895 & 24,5 & 3.650 & 100,0 \\
\hline Africa $\ldots \ldots \ldots \ldots \ldots \ldots$ & 11.289 & 75,1 & 3.736 & 24,9 & 15.025 & 100,0 \\
\hline América Norte....... & 361 & 50,1 & 360 & 49,9 & 721 & 100,0 \\
\hline América Centro..... & 702 & 18,7 & 3.051 & 81,8 & 3.753 & 100,0 \\
\hline América Sur.......... & 4.622 & 47,2 & 5.165 & 52,8 & 9.787 & 100,0 \\
\hline Asia $\ldots \ldots \ldots \ldots \ldots \ldots \ldots$ & 3.593 & 66,3 & 1.826 & 33,7 & 5.419 & 100,0 \\
\hline Oceanía................. & 15 & 45,5 & 18 & 54,5 & 33 & 100,0 \\
\hline Apátridas ............... & 6 & 100,0 & - & - & 6 & 100,0 \\
\hline No consta .............. & 53 & 60,9 & 34 & 39,1 & 87 & 100,0 \\
\hline TOTAL ................ & 23.921 & 60,6 & 15.563 & 39,4 & 39.484 & 100,0 \\
\hline
\end{tabular}

Fuente: D.G.M. Elaboración propia.

Algunos países de importante presencia en Madrid muestran un destacable desequilibrio entre los sexos. Asi, con las tasas más elevadas de masculinidad figuran, por este orden, marroquies $(77,2 \%$ de varones), polacos $(76,5 \%)$ y chinos $(72,0 \%)$. En contraste, las colonias mas femeninas son la dominicana $(85,5 \%$ de mujeres), colombiana $(62,0 \%)$, filipina $(61,3 \%)$ y peruana $(56,3 \%)$, ello sin contar algunas colonias de poco peso en el conjunto, como la caboverdiana, con la más alta representación femenina (el $88,7 \%$ de la colonia irregular madrileña son mujeres). La importante oferta de empleo en el sector del servicio doméstico dentro del municipio de Madrid y parte de su entorno metropolitano, explican el alto grado de feminización de muchas colonias.

En relación con la edad, la característica demográfica fundamental de los extranjeros en situación irregular es su juventud. El $70 \%$ de los que acudieron a la Regularización en Madrid tienen edades comprendidas entre los 20 y los 34 años, con un máximo en el grupo de 25 a 29 años, tanto entre los varones como entre las mujeres, y una edad media de 30 años. La pirámide de edades (cf . fig. 3) es un reflejo claro del carácter laboral y joven del grupo. 


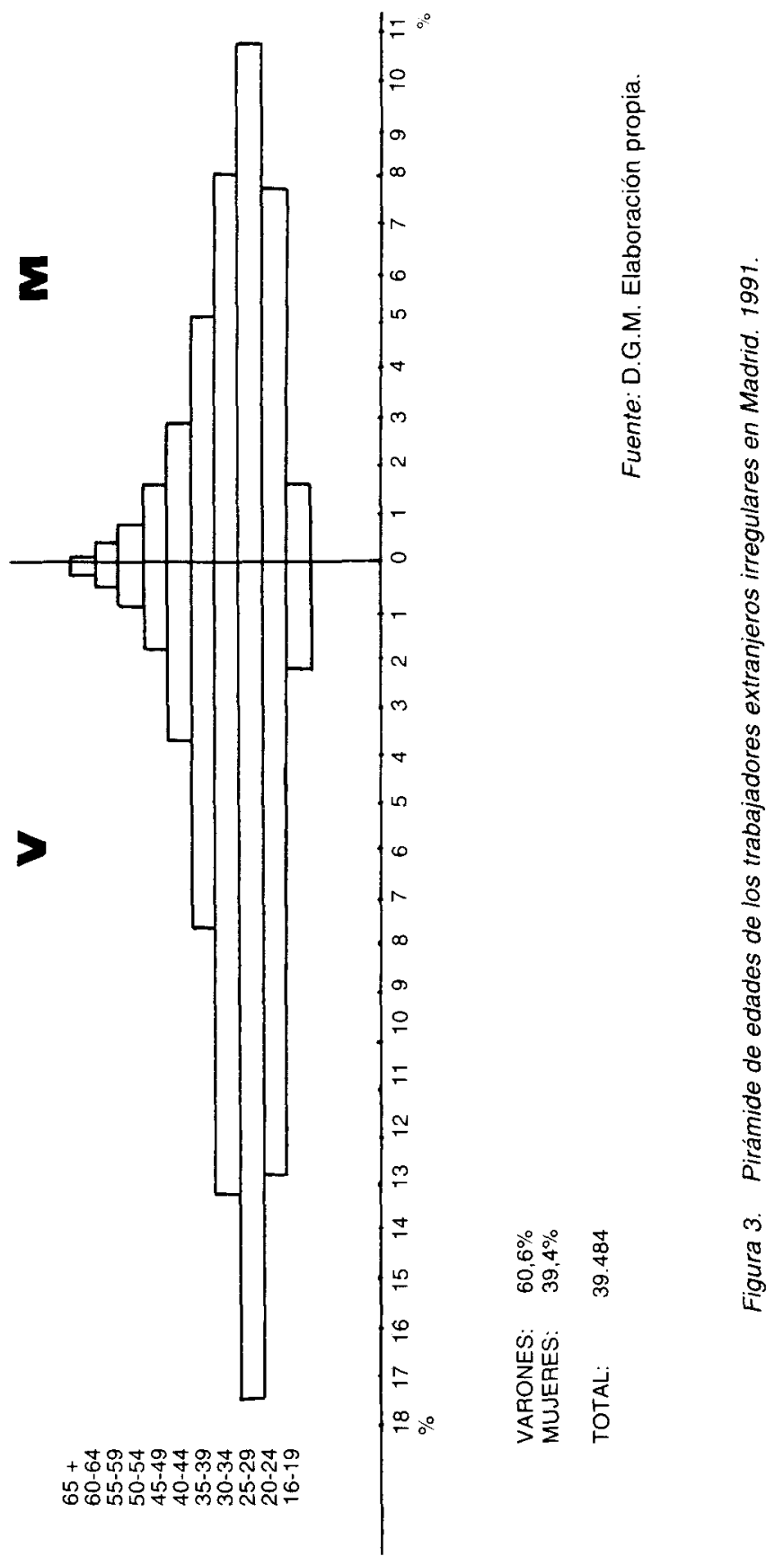


La distribución por edades es similar entre el conjunto de España y la comunidad que nos ocupa, como se observa en el cuadro $5^{9}$ y la fig. 4 . El peso de los distintos grupos es casi idéntico en los dos ámbitos espaciales, resaltando en el aspecto demográfico como diferencia fundamental únicamente el carácter más femenino de los irregulares en Madrid, frente al conjunto de España. La superposición de ambas pirámides es elocuente.

\section{CUADRO 5. TRABAJADORES EXTRANJEROS EN SITUACIÓN IRREGULAR, SEGÚN SEXO Y EDAD. MADRID/ESPAÑA (\%).}

\begin{tabular}{|c|c|c|c|c|c|c|}
\hline & \multicolumn{4}{|c|}{ MADRID } & \multicolumn{2}{|c|}{ ESPAÑA } \\
\hline & \multicolumn{2}{|c|}{ Varones } & \multicolumn{2}{|c|}{ Mujeres } & \multirow{2}{*}{$\begin{array}{c}\text { Varones } \\
\% \\
\end{array}$} & \multirow{2}{*}{$\begin{array}{c}\text { Mujeres } \\
\% \\
\end{array}$} \\
\hline & C.A. & $\%$ & C.A. & $\%$ & & \\
\hline Menores 21 a. .................. & 2.392 & 10,0 & 1.568 & 10,1 & 8,9 & 9,4 \\
\hline De 22 a 31 a. ................. & 12.769 & 53,4 & 7.888 & 50,7 & 54,3 & 49,3 \\
\hline De 32 a 41 a. .................. & 6.721 & 28,1 & 4.283 & 27,5 & 27,7 & 29,3 \\
\hline De 42 a 51 a. .................. & 1.546 & 6,5 & 1.407 & 9,1 & 6,9 & 9,3 \\
\hline Mayores de 52 a. ........... & 480 & 2,0 & 407 & 2,6 & 2,2 & 2,7 \\
\hline No consta ........................ & 13 & 0,0 & & & & \\
\hline TOTAL. & 23.921 & 100,0 & 15.563 & 100,0 & 100,0 & 100,0 \\
\hline
\end{tabular}

Fuente: D.G.M. Elaboración propia.

No puede establecerse en rigor la comparación entre censados e irregulares, por el carácter laboral de la Regularización y dado que desconocemos la distribución de los familiares en situación irregular. Sabemos que el volumen de personas que se presentaron en Madrid a la Regularización de Familiares fue de 2.141, aproximadamente el $5 \%$ del conjunto de irregulares de la comunidad, una cifra muy pequeña, que probablemente no refleja la realidad. Su distribución en la pirámide sería menos concentrada que la de trabajadores, con un máximo, seguramente, en la base, correspondiente a la población infantil.

9 Los umbrales de los grupos de edades se han acoplado a los del Informe Estadístico de Regularización de la D.G.M. para España. 


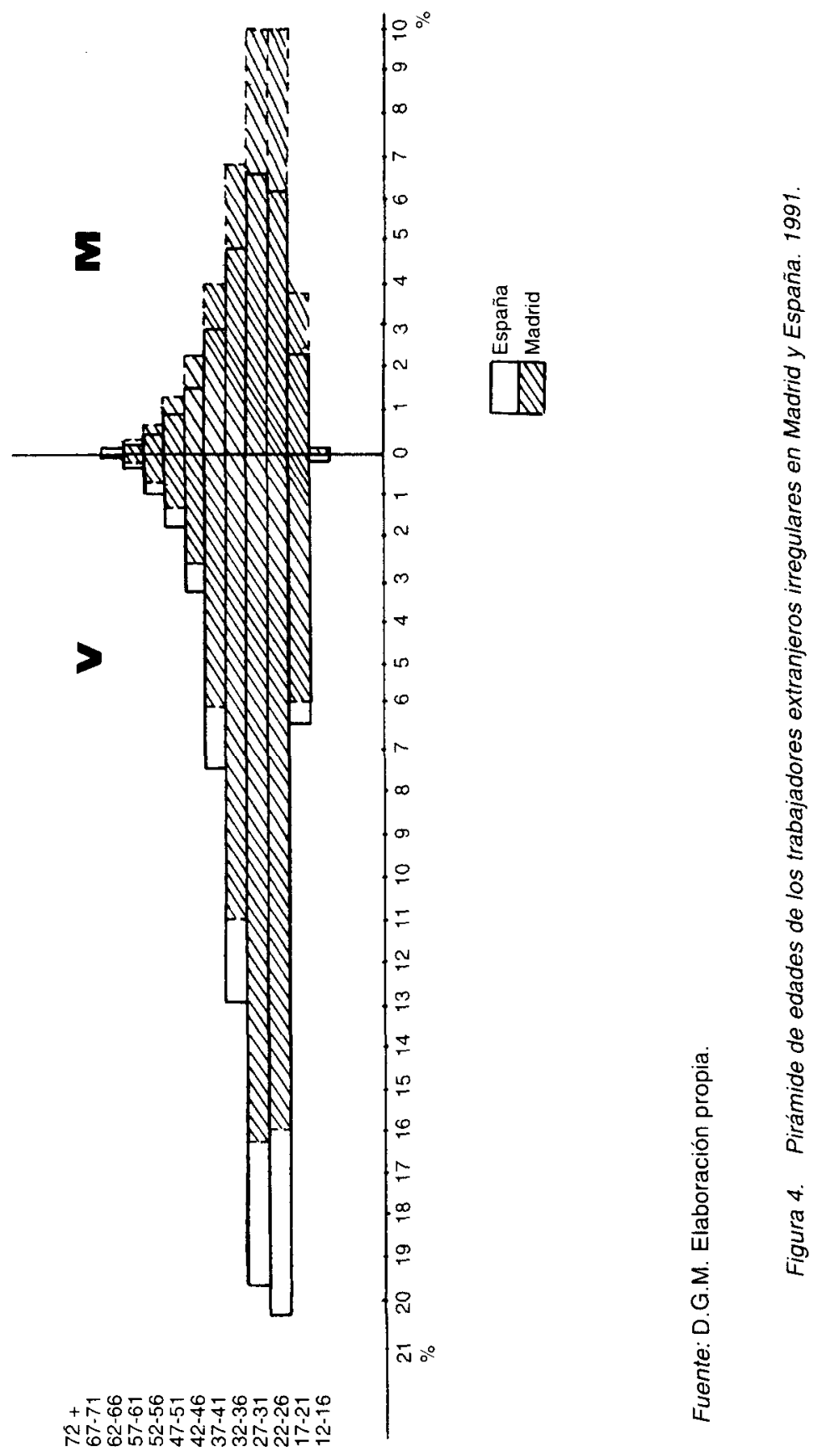


Resulta interesante, sin embargo, comparar la población activa ocupada extranjera que se inscribió en el Censo ${ }^{10}$ con los trabajadores irregulares que acudieron al proceso de Regularización, por el carácter laboral de ambos grupos (cf. fig. 5). Si bien el desequilibrio entre los sexos tiene un valor casi idéntico en los dos -entre los activos ocupados censados, el $62,1 \%$ son varones y el $37,9 \%$ mujeres, mientras entre los trabajadores irregulares los valores son de 60,6 y $39,4 \%$, respectivamente-, en lo que se refiere a la edad, el perfil destacadamente más joven de los irregulares es la característica más sobresaliente. El carácter de inmigración más reciente de la mayoría de estos últimos, unido a su procedencia de paises que configuran en España colonias muy jóvenes (G. Lora-Tamayo, 1995 b), en contraste con las más envejecidas de europeos y norteamericanos, es la explicación.

En conclusión, queda claro el carácter masculino y joven de los extranjeros en situación irregular, tanto en España como en Madrid, aunque en nuestra comunidad el peso de las mujeres es significativamente mayor que en el conjunto del país, adoptando las mismas proporciones que entre los extranjeros asentados económicamente activos. Los irregulares vienen a rejuvenecer la estructura demográfica de la población extranjera asentada, tanto en España como en Madrid.

\subsection{Estado Civil}

Como ocurría con la edad, la similitud en el estado civil de los extranjeros en situación irregular en Madrid y el conjunto de España es total (cf. cuadro 6), marcando una nota caracteristica del colectivo inmigrante en situación irregular a nivel general: se trata sobre todo de población soltera (casi dos terceras partes) y secundariamente casada (un tercio).

10 En el Censo de Población de 1991 figuran como activas 27.260 personas de nacionalidad extranjera en Madrid: un volumen significativamente menor que el de trabajadores extranjeros en situación irregular. Suponian el $44,5 \%$ del total de personas censadas. No todos los activos era población ocupada: el $85 \%-23.116$ personas - eran ocupados y el $15 \%$ restante, parados -4.144 personas-. Del conjunto de los activos, el $61,5 \%$ eran varones y el $38,5 \%$ mujeres. De los ocupados, el $60,6 \%$ eran varones y el $39,4 \%$ mujeres. En cuanto a los parados, el $58,3 \%$ eran varones y el $41,7 \%$ restante, mujeres. 


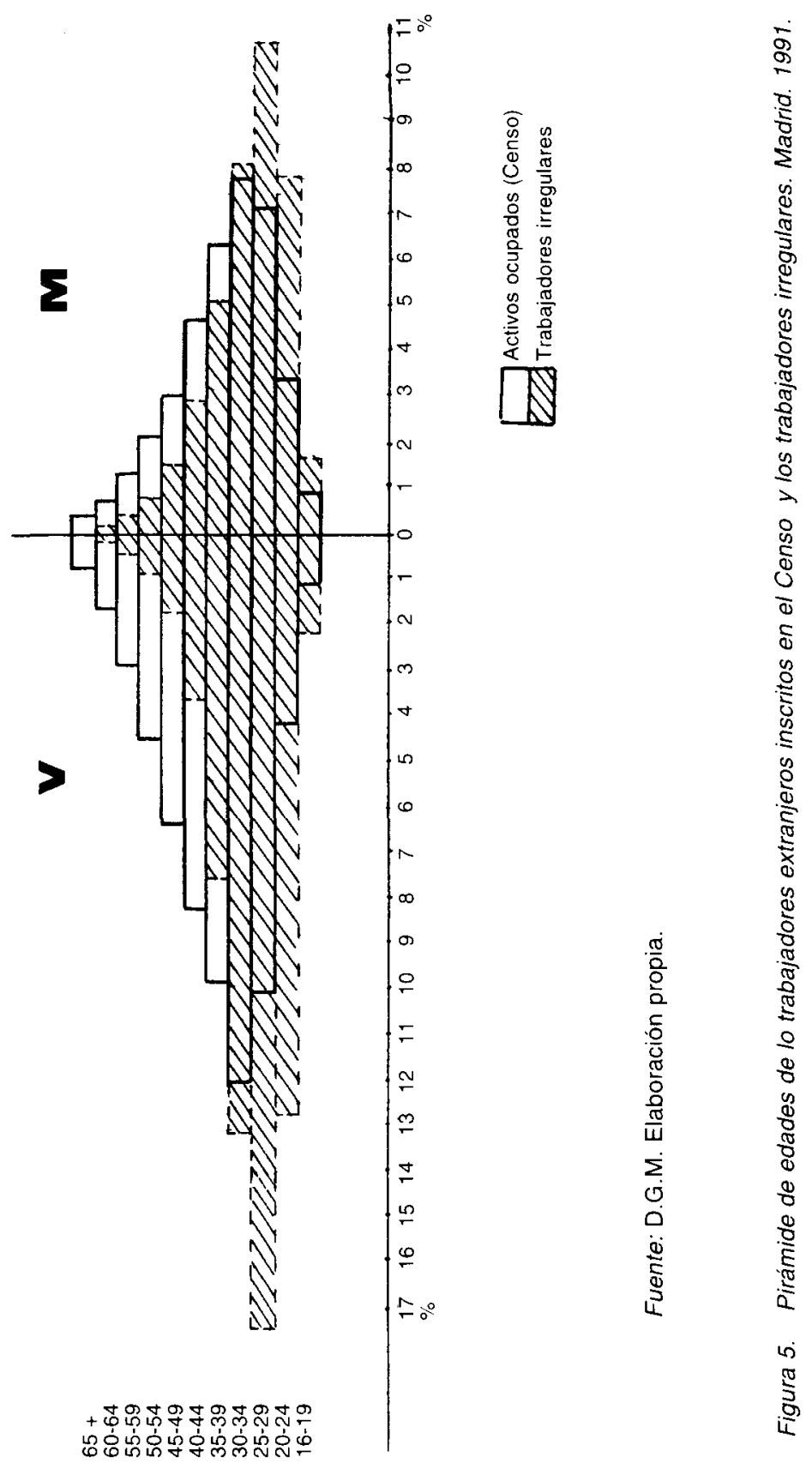


CUADRO 6. ESTADO CIVIL DE LOS TRABAJADORES EN SITUACIÓN IRREGULAR, MADRID/ESPAÑA.

\begin{tabular}{|c|c|c|c|c|}
\hline & \multicolumn{2}{|c|}{ MADRID } & \multicolumn{2}{|c|}{ ESPAÑA } \\
\hline & C.A. & $\%$ & C.A. & $\%$ \\
\hline Solteros & 25.412 & 64,4 & 81.471 & 63,6 \\
\hline Casados ........................... & 13.195 & 33,4 & 44.322 & 34,6 \\
\hline Divorciados ...................... & 464 & 1,2 & 1.304 & 1,0 \\
\hline Separados legalmente ... & 124 & 0,3 & 403 & 0,3 \\
\hline 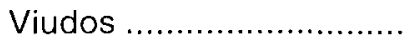 & 266 & 0,7 & 627 & 0,5 \\
\hline 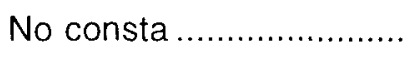 & 23 & 0,0 & & \\
\hline TOTAL. & 39.484 & 100,0 & 128.127 & 100,0 \\
\hline
\end{tabular}

Fuente: D.G.M. Elaboración propia

El predominio de la población joven que refleja la estructura por edades del grupo, es una explicación del hecho. Otra es la mayor libertad para emigrar en condiciones de menor seguridad por parte de los solteros, sin cargas familiares, que de los casados.

Centrándonos en Madrid, existe un claro contraste en el estado civil entre los irregulares y la población extranjera que se inscribió en el Censo (C.A.M.): en éstos, las proporciones de casados y solteros son casi idénticas $-47,3 \%$ y $46,4 \%$, respectivamente-. Viudos, separados y divorciados, están más representados entre la población asentada que entre los irregulares: $3,4 \%$ de viudos entre los censados, frente a $0,7 \%$ entre los irregulares y $2,8 \%$ de separados y divorciados entre los primeros, frente a $1,5 \%$ entre los irregulares.

Por último, la distribución de la variable muestra diferencias notables entre los sexos en el grupo de los irregulares (cf. fig. 6): así las mujeres en esta situación son mayoritariamente solteras $-71,4 \%$, que contrasta con el $59,9 \%$ de varones solteros--.Son casadas sólo una cuarta parte de las mujeres, frente al $39,2 \%$ de los hombres. Por último, el grupo de divorciados o separados tiene una mayor representación entre las mujeres que entre los varones: $4,0 \%$, frente a $0,9 \%$, respectivamente.

De todo lo expuesto se puede concluir que la inmigración económica de carácter laboral en situación irregular se da sobre todo en individuos sin cargas familiares - solteros-que pueden lanzarse a la aventura con mayor libertad. Entre las mujeres esto es aun más claro. En el caso de los casados, la inmigración irregular es mucho más frecuente entre los varones: de los 13.195 extranjeros irregulares registrados en Madrid, el $71 \%$ 


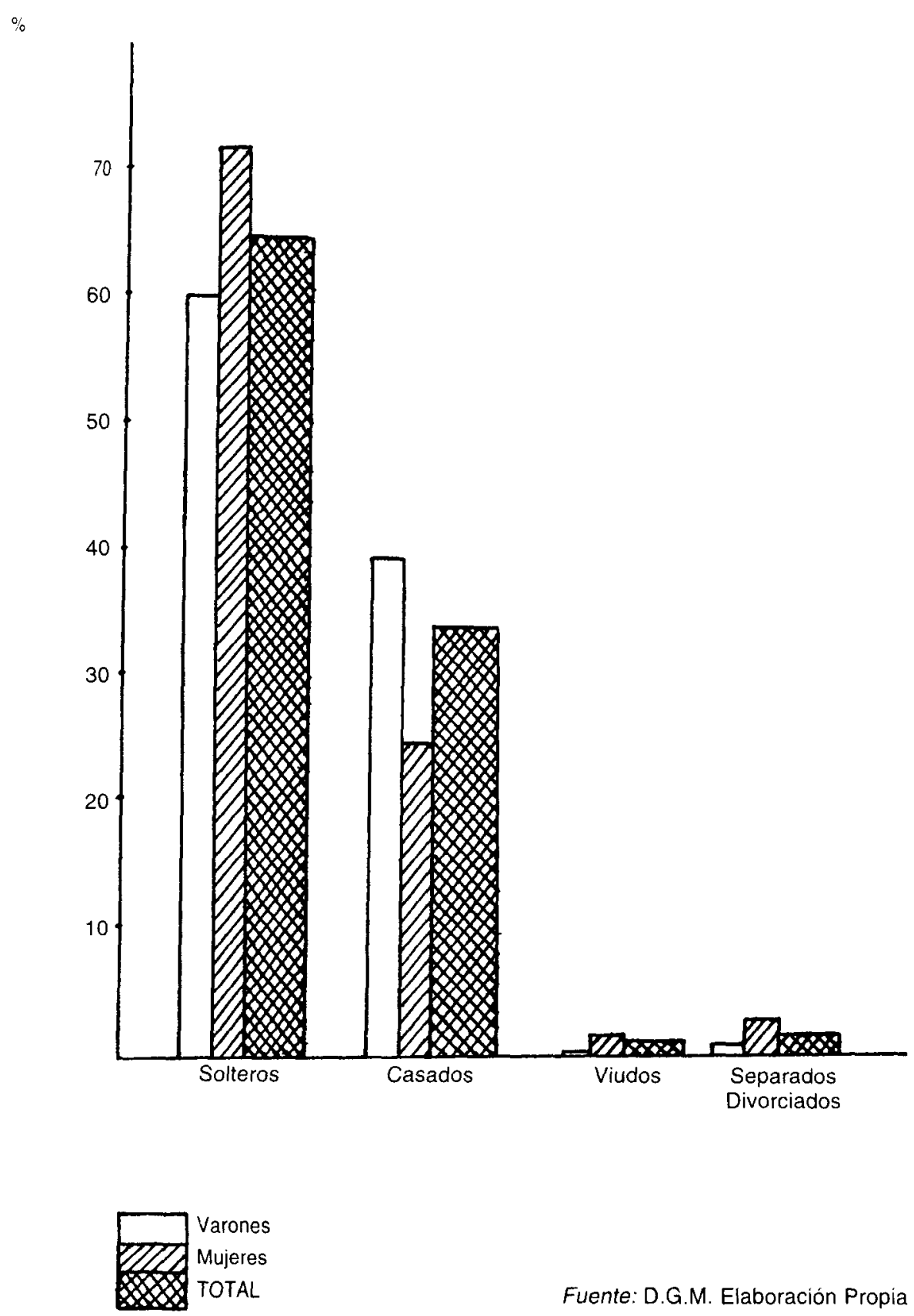

Figura 6. Estado civil de los extranjeros en situación irregular en Madrid. 1991. 
son varones y sólo el $29 \%$ mujeres; recordemos que uno de los esquemas migratorios típicos, en el que se encuadran sobre todo los nacionales de Marruecos, es el del varón casado que emigra solo, dejando atrás a la familia, a la que provee desde su destino de lo necesario hasta que, bien retorna, bien está en condiciones de reagruparla. El caso de mujeres casadas emigrando solas es mucho menos frecuente, aunque está muy extendido entre la población dominicana y, en menor medida, la filipina, en ambos casos por la oportunidad que representa el trabajo en el servicio doméstico (G. Lora-Tamayo, 1995; Y. Herranz, 1993).

\subsection{Caracteristicas laborales}

Las variables que se analizan en relación con las características laborales de los extranjeros en situación irregular son las que investiga la D.G.M.: clase de permiso, ocupación y actividad económica.

\subsubsection{Clase de permiso}

Los permisos solicitados en la operación de Regularización tuvieron en todos los casos una validez de un año. Se expidieron dos tipos: por cuenta ajena y por cuenta propia. La mayor parte de los solicitados fueron para trabajar por cuenta ajena -36.602, el 92,7\%-, siendo reducido el número de los solicitados para trabajar por cuenta propia -2.882, el 7,3\%-.

En este sentido, existe un importante contraste entre Madrid y España, siendo el peso de los permisos por cuenta propia en el conjunto del país muy superior $(20,1 \%)$. Este hecho incidió en el numero de denegaciones, que fue mas elevado en España que en Madrid (14,1\% y 9,5\%, respectivamente), ya que las concesiones recayeron sobre todo en lo permisos por cuenta ajena

\subsubsection{Ocupación}

Los trabajadores extranjeros en situación irregular en Madrid se ocupan fundamentalmente en la hostelería y los servicios y secundariamente en la construcción, industria, minería y transporte.

Se trata de ocupaciones, por lo general, de escasa o nula cualificación. El cuadro 7 muestra el reducido volumen de irregulares encuadrados en los dos primeros grupos de la clasificación, que suponen las ocupaciones de mayor rango: (1) profesionales y (2) miembros del gobierno o directivos y gerentes de empresas públicas y privadas. Más adelante se 
analizará el contraste entre los irregulares y la población extranjera ocupada que se inscribió en el Censo.

La confrontación entre los irregulares de Madrid y los del conjunto de España señala diferencias importantes (cf. cuadro 7 y fig. 7): el peso de las ocupaciones relacionadas con la hostelería y los servicios es superior en nuestra comunidad. En el conjunto del país, sin embargo, existe una mayor diversificación ocupacional, con una representación significativa de los agricultores y ganaderos, por una parte, y los agentes comerciales y vendedores, por otra, además de los trabajadores de la hostelería y servicios y de la construcción, minería, industria y transporte, como en la comunidad que nos ocupa.

CUADRO 7. TRABAJADORES EXTRANJEROS IRREGULARES SEGUN SU OCUPACIÓN (C.N.O.) EN MADRID Y ESPAÑA, 1991.

\begin{tabular}{|c|c|c|c|}
\hline & \multicolumn{2}{|c|}{ MADRID } & \multirow{2}{*}{$\frac{\text { ESPANA }}{\%}$} \\
\hline & C.A. & $\%$ & \\
\hline 1) Profesionales, técnicos y similares ... & 3.451 & 8,7 & 6,9 \\
\hline $\begin{array}{l}\text { 2) Directivos de organismos públicos } \\
\text { y privados }\end{array}$ & 470 & 1,2 & 1,3 \\
\hline 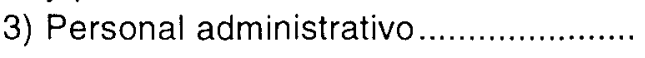 & 1.946 & 4,9 & 3,3 \\
\hline $\begin{array}{l}\text { 4) Agentes comerciales, dependientes } \\
\text { y vendedores }\end{array}$ & 2.065 & 5,2 & 10,8 \\
\hline 5) Trabajadores de la hostelería y los & & & \\
\hline servicios & 19.810 & 50,2 & 34,2 \\
\hline 6) Agricultores y ganaderos $\ldots \ldots \ldots \ldots \ldots \ldots$ & 1.995 & 5,1 & 17,8 \\
\hline $\begin{array}{l}\text { 7) Trab. de la construcción, industria, } \\
\text { minería y transporte }\end{array}$ & 9.564 & 24,2 & 24,9 \\
\hline Ocupaciones no bien especificadas ....... & 160 & 0,5 & 0,8 \\
\hline 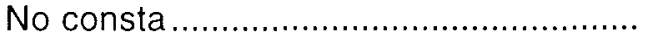 & 23 & - & - \\
\hline TOTAL.. & 39.484 & 100,0 & 100,0 \\
\hline
\end{tabular}

Fuente: D.G.M. Elaboración propia.

Como cabía esperar, se da una marcada diferenciación ocupacional en función del sexo (cf. cuadro 8). Mientras los hombres se encuadran sobre todo en los grupos 7 y 5 , las mujeres se asocian mayoritariamente al trabajo en la hostelería y los servicios, en particular al servicio doméstico, que aglutina a las tres cuartas partes de las mujeres extranjeras en situación irregular. 


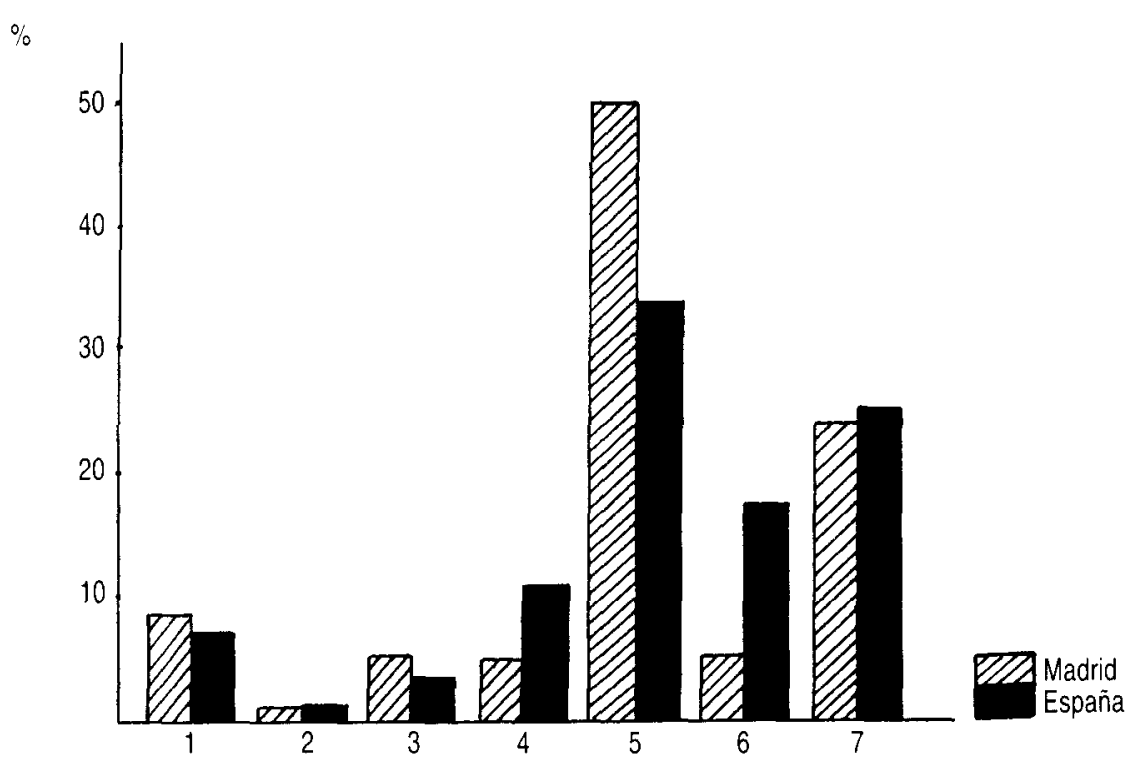

Clasificación de Ocupaciones (C.N.O.):

1 Profesionales, técnicos y similares

2 Directivos de Organismos públicos y privados

3 Personal administrativo

4 Agentes comerciales, dependientes y vendedores

Fuente: D.G.M. Elaboración Propia
5 Trabajadores de la hosteleria y de los servicios 6 Agricultores y ganaderos

7 Trabajadores de la construcción, industria, mineria y transporte.

Figura 7. Trabajadores extranjeros irregulares, según su ocupación, en Madrid y España. 1991.

A nivel de epígrafes de la clasificación, dentro de los grupos generales, las ocupaciones más representadas entre los irregulares de Madrid son el servicio doméstico, con casi un tercio de trabajadores - una mayoria de mujeres-, la construcción - hombres en su totalidad-y los cocineros y camareros - mayoritariamente varones-. Las dos últimas ocupaciones acaparan a la cuarta parte del conjunto, como se observa en el cuadro 9. En España los irregulares no tienen pesos tan elevados en ningún subsector de ocupación, aunque también alcanzan valores significativos el personal del servicio doméstico — con proporciones inferiores a las de Madrid-, los trabajadores de la construcción y cocineros, camareros y similares, además de los trabajadores agrícolas y ganaderos, comerciantes y vendedores y el personal de servicios diversos. Mientras tres ocupaciones concentran en Madrid el $60 \%$ de los trabajadores extranjeros en situación irregular, en 
España son seis las ocupaciones más importantes, concentrando en conjunto a casi las tres cuartas partes de los irregulares.

CUADRO 8. TRABAJADORES EXTRANJEROS IRREGULARES EN MADRID, SEGUN SU OCUPACIÓN, POR SEXO, 1991.

\begin{tabular}{|c|c|c|c|c|c|c|}
\hline & \multicolumn{2}{|c|}{ VARONES } & \multicolumn{2}{|c|}{ MUJERES } & \multicolumn{2}{|c|}{ TOTAL } \\
\hline & C.A. & $\%$ & C.A. & $\%$ & C.A. & $\%$ \\
\hline 1). & 2.137 & 8,9 & 1.314 & 8,4 & 3.451 & 8,7 \\
\hline (n.................. & 353 & 1,5 & 117 & 0,7 & 470 & 1,2 \\
\hline 3). & 940 & 3,9 & 1.006 & 6,5 & 1.946 & 4,9 \\
\hline 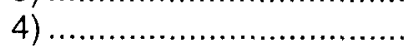 & 1.709 & 7,1 & 356 & 2,3 & 2.065 & 5,2 \\
\hline 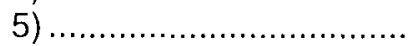 & 7.389 & 30,9 & 12.421 & 79,8 & 19.810 & 50,2 \\
\hline 6) & 1.955 & 8,2 & 40 & 0,3 & 1.995 & 5,1 \\
\hline 7) & 9.308 & 38,9 & 256 & 1,6 & 9.564 & 24,2 \\
\hline Oc. no bien espec. ......... & 117 & 0,5 & 43 & 0,3 & 160 & 0,4 \\
\hline No consta ..................... & 13 & 0,1 & 10 & 0,1 & 23 & 0,1 \\
\hline TOTAL. & 23.921 & 100,0 & 15.563 & 100,0 & 39.484 & 100,0 \\
\hline
\end{tabular}

Fuente: D.G.M. Elaboración propia.

CUADRO 9. OCUPACIONES MAS REPRESENTADAS ENTRE LOS TRABAJADORES EXTRANJEROS IRREGULARES. SUBSECTORES. MADRID/ESPAÑA, 1991.

\begin{tabular}{|c|c|c|c|}
\hline & \multicolumn{2}{|c|}{ MADRID } & \multirow{2}{*}{$\frac{\text { ESPAÑA }}{\%}$} \\
\hline & C.A. & $\%$ & \\
\hline Encargados y personal serv. doméstico & 12.508 & 31,7 & 18,2 \\
\hline Trabajadores de la construcción .................. & 5.754 & 14,6 & 13,4 \\
\hline Cocineros, camareros y similares ............... & 4.675 & 11,9 & 10,5 \\
\hline Personal de servicios diversos.................... & 1.857 & 4,7 & 8,1 \\
\hline Empleados de los serv. administrativos ....... & 1.346 & 3,4 & 2,4 \\
\hline Comerciantes y vendedores.......................... & 1.099 & 2,8 & 8,3 \\
\hline Trabajadores agrícolas, ganaderos y similares & 1.001 & 2,5 & 14,5 \\
\hline Trabajadores forestales.............................. & 974 & 2,5 & 2,8 \\
\hline
\end{tabular}

Fuente: D.G.M. Elaboración propia.

Se observan diferencias en las ocupaciones preferentes de las distintas colonias de trabajadores irregulares de Madrid (cf. cuadro 10). Asi, por ejemplo, mientras los nacionales de Oceania y los Norteamericanos son mayoritariamente profesionales, centroamericanos y asiáticos son trabajadores de la hostelería y los servicios. 
En general, todas las colonias de irregulares cuentan con una proporción significativa de trabajadores de la hosteleria y los servicios, destacando dentro de esta ocupación los empleados del servicio doméstico, los cocineros y los camareros. Los trabajadores de la construcción, industria, minería y transporte están muy representados entre los nacionales del resto de Europa y, secundariamente, entre los africanos: dentro de este grupo destaca como ocupación primordial en todas las colonias la construcción, constituyendo la actividad industrial una ocupación muy secundaria. En cuanto a los trabajadores agrícolas, ganaderos y forestales, únicamente cabe destacar a la colonia africana, debiendo advertirse que muchas de las personas que declaran esta ocupación trabajan realmente como jardineros. Por último, el personal administrativo no se halla muy representado entre los irregulares, si bien alcanza las mayores proporciones entre los nacionales de Oceania, norteamericanos y sudamericanos.

\section{CUADRO 10. TRABAJADORES EXTRANJEROS IRREGULARES EN MADRID SEGÚN SU OCUPACIÓN, POR CONTINENTE DE NACIONALIDAD, 1991.}

\begin{tabular}{|c|c|c|c|c|c|c|c|c|c|c|}
\hline & C.E. & $\begin{array}{l}\text { RESTO } \\
\text { EUROPA }\end{array}$ & AFRICA & $\begin{array}{c}\text { AMERICA } \\
\text { NORTE }\end{array}$ & $\begin{array}{l}\text { AMERICA } \\
\text { CENTRAL }\end{array}$ & $\begin{array}{c}\text { AMERICA } \\
\text { SUR }\end{array}$ & ASIA & OCEANIA & APAT. & TOTAL \\
\hline (1) $\ldots \ldots \ldots \ldots . .$. & $\begin{array}{r}232 \\
20,9\end{array}$ & $\begin{array}{r}233 \\
6,4\end{array}$ & $\begin{array}{r}420 \\
2,8\end{array}$ & $\begin{array}{r}416 \\
52,3\end{array}$ & $\begin{array}{r}205 \\
5,5\end{array}$ & $\begin{array}{r}1.699 \\
17,4\end{array}$ & $\begin{array}{r}214 \\
4,0\end{array}$ & $\begin{array}{r}24 \\
68,6\end{array}$ & $\begin{array}{r}8 \\
16,7\end{array}$ & $\begin{array}{r}3.451 \\
8,7\end{array}$ \\
\hline (2) $\ldots \ldots \ldots \ldots$ & $\begin{array}{r}21 \\
1,9\end{array}$ & $\begin{array}{l}26 \\
0,7\end{array}$ & $\begin{array}{r}35 \\
0,2\end{array}$ & $\begin{array}{r}31 \\
3,9\end{array}$ & $\begin{array}{r}12 \\
0,3\end{array}$ & $\begin{array}{r}185 \\
1,9\end{array}$ & $\begin{array}{r}156 \\
2,9\end{array}$ & $\begin{array}{r}1 \\
2,9\end{array}$ & $\begin{array}{r}3 \\
6,2\end{array}$ & $\begin{array}{r}470 \\
1,2\end{array}$ \\
\hline (3) $\begin{array}{r}\ldots \ldots \ldots \ldots \\
\% \ldots \ldots \ldots\end{array}$ & $\begin{array}{r}64 \\
5,8\end{array}$ & $\begin{array}{r}168 \\
4,6\end{array}$ & $\begin{array}{r}336 \\
2,2\end{array}$ & $\begin{array}{r}101 \\
12,7\end{array}$ & $\begin{array}{r}89 \\
2,4\end{array}$ & $\begin{array}{r}932 \\
9,6\end{array}$ & $\begin{array}{r}246 \\
4,6\end{array}$ & $\begin{array}{r}5 \\
14,3\end{array}$ & $\begin{array}{r}5 \\
10,4\end{array}$ & $\begin{array}{r}1.946 \\
4,9\end{array}$ \\
\hline 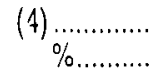 & $\begin{array}{r}33 \\
3,0\end{array}$ & $\begin{array}{r}91 \\
2,5\end{array}$ & $\begin{array}{r}960 \\
6,4\end{array}$ & $\begin{array}{l}37 \\
4,6\end{array}$ & $\begin{array}{l}53 \\
1,4\end{array}$ & $\begin{array}{r}564 \\
5,8\end{array}$ & $\begin{array}{r}324 \\
6,0\end{array}$ & - & $\begin{array}{r}3 \\
6,2\end{array}$ & $\begin{array}{r}2.065 \\
5,2\end{array}$ \\
\hline 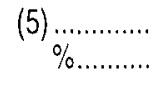 & $\begin{array}{r}606 \\
54,6\end{array}$ & $\begin{array}{r}1.114 \\
30,5\end{array}$ & $\begin{array}{r}5.833 \\
38,9\end{array}$ & $\begin{array}{r}157 \\
19,7\end{array}$ & $\begin{array}{r}3.129 \\
84,0\end{array}$ & $\begin{array}{r}5.042 \\
51,8\end{array}$ & $\begin{array}{r}3.911 \\
73,0\end{array}$ & $\begin{array}{r}4 \\
11,4\end{array}$ & $\begin{array}{r}14 \\
29,2\end{array}$ & $\begin{array}{r}19.810 \\
50,2\end{array}$ \\
\hline (6) $\ldots \ldots \ldots \ldots$ & $\begin{array}{r}9 \\
0,8\end{array}$ & $\begin{array}{r}86 \\
2,3\end{array}$ & $\begin{array}{r}1.790 \\
11,9\end{array}$ & $\begin{array}{r}2 \\
0,2\end{array}$ & $\begin{array}{l}23 \\
0,6\end{array}$ & $\begin{array}{r}60 \\
0,6\end{array}$ & $\begin{array}{l}25 \\
0,5\end{array}$ & - & - & $\begin{array}{r}1.995 \\
5,1\end{array}$ \\
\hline (7) $\ldots \ldots \ldots$ & $\begin{array}{r}139 \\
12,6\end{array}$ & $\begin{array}{r}1.927 \\
52,7\end{array}$ & $\begin{array}{r}5.569 \\
37,1\end{array}$ & $\begin{array}{r}45 \\
5,7\end{array}$ & $\begin{array}{r}207 \\
5,5\end{array}$ & $\begin{array}{r}1.201 \\
12,3\end{array}$ & $\begin{array}{r}461 \\
8,6\end{array}$ & - & $\begin{array}{r}15 \\
31,2\end{array}$ & $\begin{array}{r}9.564 \\
24,2\end{array}$ \\
\hline $\begin{array}{r}\text { O.n.be....... } \\
\% \ldots \ldots . . . . .\end{array}$ & $\begin{array}{r}5 \\
0,4\end{array}$ & $\begin{array}{r}12 \\
0,3\end{array}$ & $\begin{array}{l}51 \\
0,3\end{array}$ & $\begin{array}{r}7 \\
0,9\end{array}$ & $\begin{array}{r}6 \\
0,2\end{array}$ & $\begin{array}{r}54 \\
0,6\end{array}$ & $\begin{array}{l}24 \\
0,4\end{array}$ & $\begin{array}{r}1 \\
2,8\end{array}$ & - & $\begin{array}{r}160 \\
0,4\end{array}$ \\
\hline $\begin{array}{r}\text { N.C. } \\
\% \ldots \ldots \ldots . . . . . . . . \\
\end{array}$ & & & & & & & & & & $\begin{array}{r}\ldots \ldots .23 \\
\ldots \ldots .0,1 \\
\ldots\end{array}$ \\
\hline $\begin{array}{r}\text { TOTAL ......... } \\
\% \ldots \ldots \ldots . . .\end{array}$ & $\begin{array}{l}1.109 \\
(100)\end{array}$ & $\begin{array}{l}3.657 \\
(100)\end{array}$ & $\begin{array}{r}14.994 \\
(100)\end{array}$ & $\begin{array}{r}796 \\
(100)\end{array}$ & $\begin{array}{l}3.724 \\
(100)\end{array}$ & $\begin{array}{l}9.737 \\
(100)\end{array}$ & $\begin{array}{l}5.361 \\
(100)\end{array}$ & $\begin{array}{r}35 \\
(100)\end{array}$ & $\begin{array}{r}48 \\
(100)\end{array}$ & $\begin{array}{r}39.484 \\
(100)\end{array}$ \\
\hline
\end{tabular}

Fuente: D.G.M. Elaboración propia. 
Entre las colonias más representadas a nivel de pais, existen polarizaciones ocupacionales claras. Asi, el caso de las colonias filipina, dominicana, portuguesa y china, cuyos componentes son empleados de los servicios domésticos, cocineros y camareros en un $87 \%, 83 \%, 78 \%$ y $74 \%$, respectivamente. Las tres primeras tienen una mayoria de trabajadores del servicio doméstico, mientras en la última dominan los camareros y cocineros, sin duda en relación con los restaurantes chinos, muy extendidos sobre todo en la capital.

También entre las colonias sudamericanas este tipo de ocupación es destacable: el $53,5 \%$ de los peruanos, el $52,5 \%$ de los colombianos y el $45,7 \%$ de los chilenos irregulares en Madrid son empleados del servicio doméstico, camareros o cocineros. Sin embargo, en estas colonias una parte de los trabajadores son administrativos, comerciantes e incluso profesionales. La cuarta colonia de importante representación en Madrid, la argentina, tiene un carácter totalmente diferente, como se ha señalado en anteriores investigaciones (Y. Herranz Gómez, , 1993, G. Lora-Tamayo, 1995 b). Entre los irregulares argentinos, igual que entre la población asentada, se da casi un tercio de profesionales - músicos y artistas, médicos, ingenieros y arquitectos, profesores... - y una amplia diversificación en el resto de los grupos ocupacionales. Los argentinos, dentro de las colonias de más fuerte presencia en Madrid, tanto en lo que se refiere a los irregulares como, sobre todo, a los regulares, muestran, en líneas generales, un alto nivel socioeconómico.

Las colonias anteriormente citadas, a excepción de la argentina, reflejaban una fuerte polarización hacia las ocupaciones relacionadas con la hostelería y los servicios. Ello explica la gran presencia de mujeres en ellas - salvo en la china, hostelera más que dedicada a los servicios domésticos, como las restantes-. Las colonias polaca y marroquí, claramente masculinas, tienen una mayor diversificación ocupacional, mostrando una fuerte atracción por los trabajos relacionados con la construcción, la industria, la minería y el transporte. Así, los trabajadores polacos irregulares eran en un $31 \%$ trabajadores de la industria, minería y transporte, en un $27 \%$ de la construcción y en un $23 \%$ del servicio doméstico, cocineros y camareros. Por su parte, los marroquíes eran en una tercera parte trabajadores de la construcción, en más de una cuarta parte trabajadores del servicio doméstico, cocineros y camareros, en un $14 \%$ trabajadores agrícolas, ganaderos y similares y en un $8 \%$ trabajadores de la industria.

El contraste fundamental en lo que se refiere a la ocupación de la población extranjera que trabaja en Madrid, se da entre los irregulares y los 
asentados: aparte la mayor diversificación, el peso entre estos últimos de ocupaciones de mayor cualificación marca la diferencia más notable (cf. cuadro 11).

CUADRO 11. TRABAJADORES EXTRANJEROS IRREGULARES $Y$ CENSADOS EN MADRID, SEGUN SU OCUPACIÓN, 1991.

\begin{tabular}{|c|c|c|c|c|}
\hline & \multicolumn{2}{|c|}{ IRREGULARES } & \multicolumn{2}{|c|}{ CENSADOS } \\
\hline & C.A. & $\%$ & C.A. & $\%$ \\
\hline (1) $\ldots \ldots \ldots \ldots \ldots \ldots$ & 3.451 & 8,7 & 7.629 & 33,0 \\
\hline (2) $\ldots \ldots \ldots \ldots \ldots$ & 470 & 1,2 & 1.904 & 8,2 \\
\hline 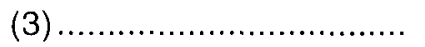 & 1.946 & 4,9 & 2.794 & 12,1 \\
\hline 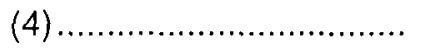 & 2.065 & 5,2 & 2.301 & 10,0 \\
\hline (5) & 19.810 & 50,2 & 5.060 & 21,9 \\
\hline 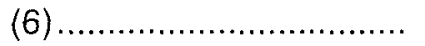 & 1.995 & 5,1 & 163 & 0,7 \\
\hline (7) $\ldots \ldots \ldots \ldots \ldots \ldots \ldots \ldots \ldots \ldots \ldots \ldots \ldots \ldots \ldots \ldots \ldots \ldots$ & 9.564 & 24,2 & 3.057 & 13,2 \\
\hline FFAA $\ldots \ldots \ldots \ldots \ldots \ldots \ldots \ldots \ldots \ldots \ldots \ldots$ & - & - & 208 & 0,9 \\
\hline Oc. no bien especificadas & 160 & 0,4 & - & - \\
\hline No consta ......................... & 23 & 0,1 & - & 二 \\
\hline TOTAL... & 39.484 & 100,0 & 23.116 & 100,0 \\
\hline
\end{tabular}

Fuente: D.G.M. e I.N.E. Elaboración propia

La confrontación de ambas estructuras ocupacionales viene a reflejar, en definitiva, la distinta procedencia mayoritaria de ambos grupos de trabajadores, con el gran peso de colonias procedentes de paises subdesarrollados o en vías de desarrollo entre los irregulares, frente al peso destacado de los paises ricos en el grupo de los censados.

Observando la estructura ocupacional diferencial de irregulares y censados a nivel de continentes de nacionalidad (cf. fig.8), existen mayores similitudes, si bien subsisten diferencias notables, básicamente imputables a que los paises más representados dentro de cada continente no son los mismos entre los irregulares y los censados. Asi, por ejemplo, los portugueses suponen el $63 \%$ de los irregulares nacionales de la C.E. y sólo el $12,2 \%$ de los censados, por lo que el bloque de comunitarios irregulares refleja en gran medida las características de la colonia portuguesa, mientras el de los comunitarios censados refleja de forma más clara las de los paises desarrollados de Europa Occidental. Algo parecido ocurre con el resto de Europa: entre los irregulares, el $72 \%$ son polacos, mientras entre los censados éstos no representan más que el $29 \%$, siendo mayoría en el grupo otros paises desarrollados del occidente europeo. 


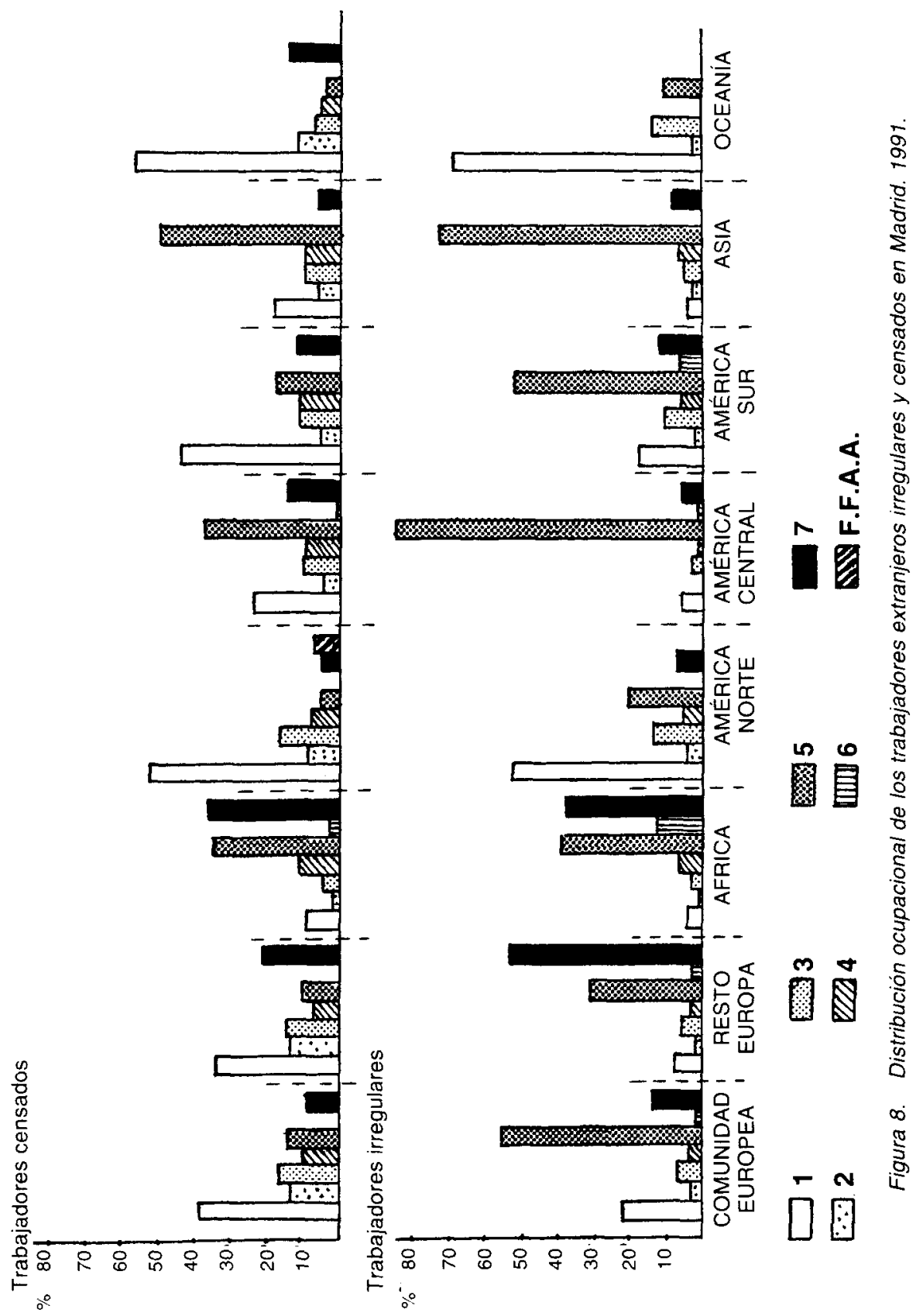


También en el caso de América Central, los irregulares reflejan básicamente las características de la colonia dominicana -que representa el $87,5 \%$ del conjunto-, mientras los censados tienen una mayor diversificación nacional. En América del Sur, la colonia con un mayor status socioprofesional, Argentina, está más representada entre los censados $(37,2 \%)$ que entre los irregulares $(23,6 \%)$, dentro de los cuales tiene un fuerte peso la colonia peruana, cuyas características ya conocemos.

Por último, entre los asiáticos irregulares, China es el país más representado, seguido de Filipinas. Ambas, colonias con perfiles ocupacionales muy concretos; entre los censados, Filipinas adquiere mayor protagonismo, seguida de una diversidad de colonias.

Asi pues, las diferencias entre irregulares y censados, al margen de que puedan reflejar, en parte, polos opuestos de una misma colonia, muestran con claridad, y sobre todo, el contraste nítido entre las colonias de inmigrantes económicos frente a las de extranjeros asentados. De alguna manera, son una imagen del carácter dual del mercado de trabajo español, y más concretamente madrileño, en relación con la población activa extranjera: empleos de elevada cualificación, ligados con frecuencia al capital extranjero y ocupados por nacionales de paises desarrollados -básicamente la U.E., la EFTA, Estados Unidos y Japón-, en relación con empresas de servicios e industrias punta, a lo que se unen profesionales de algunos paises latinoamericanos -Argentina y Méjico, sobre todo ( $G$. Lora-Tamayo, 1995 a y b) -, frente a empleos de escasa o nula cualificación y con frecuencia de carácter precario, con altos indices de paro y eventualidad. Estos últimos son ocupados por trabajadores procedentes del Tercer mundo, básicamente africanos, portugueses, dominicanos, polacos y chinos, la mayor parte de los cuales se halla en situación irregular.

\subsubsection{Rama de Actividad Económica}

La rama de actividad económica en que se encuadran con preferencia los trabajadores extranjeros en situación irregular en Madrid es, como cabe suponer, la de "Otros servicios", grupo amplio que engloba actividades relacionados con el transporte, la banca, educación, sanidad, asistencia social, y un largo etcétera, además de los servicios domésticos y personales (cf. cuadro 12 y fig. 9).

La distribución por ramas de la población trabajadora en situación irregular es más diversificada en España que en la comunidad que nos ocupa, teniendo una mayor representación los sectores agrícola y comercial y menor el sector servicios. Los epigrafes de mayor adscripción dentro de 
estos grandes grupos son, como se observa en el cuadro 13, los de servicios domésticos, construcción y hostelería en Madrid, los mismos que en España, donde además la producción agrícola y el comercio minorista tienen un papel destacado.

CUADRO 12. TRABAJADORES IRREGULARES SEGUN RAMA DE ACTIVIDAD, EN MADRID Y ESPAÑA, 1991.

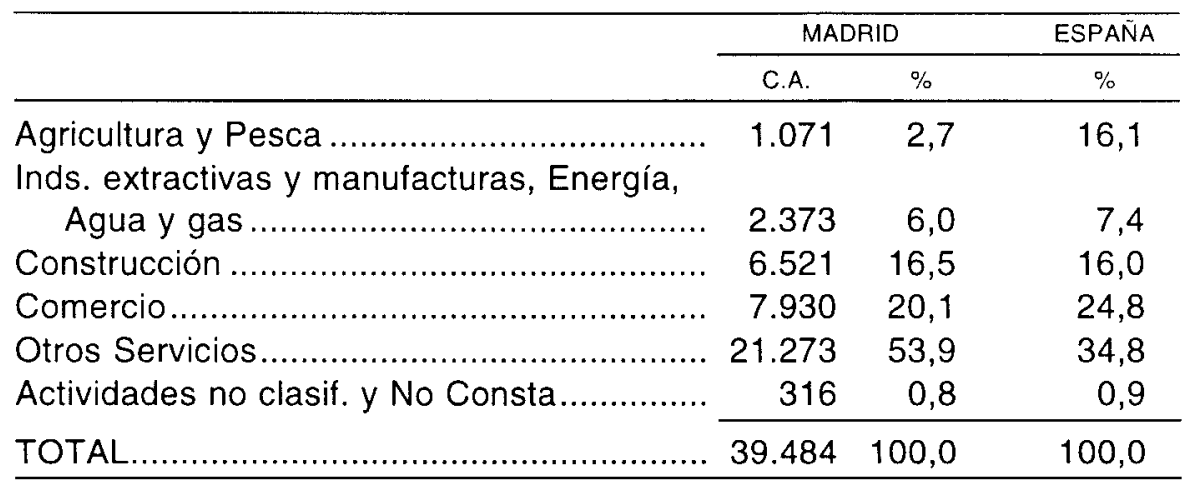

Fuente: D.G.M. Elaboración propia.

CUADRO 13. SUBSECTORES DE ACTIVIDAD MAS REPRESENTADOS ENTRE LOS TRABAJADORES EXTRANJEROS IRREGULARES EN MADRID Y ESPAÑA, 1991.

\begin{tabular}{|c|c|c|c|}
\hline & \multicolumn{2}{|c|}{ MADRID } & \multirow{2}{*}{$\begin{array}{c}\text { ESPAÑA } \\
\%\end{array}$} \\
\hline & C.A. & $\%$ & \\
\hline Producción agrícola & 734 & 1,9 & 13,6 \\
\hline Construcción ............. & 6.521 & 16,5 & 16,0 \\
\hline Comercio Minorista . & 1.678 & 4,2 & 10,1 \\
\hline 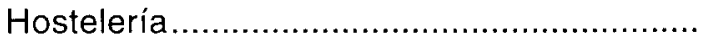 & 5.267 & 13,3 & 12,1 \\
\hline Servicios prestados a las empresas............. & 4.454 & 11,3 & 8,0 \\
\hline 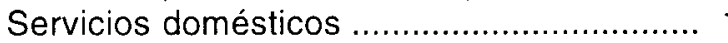 & 13.391 & 33,9 & 20,3 \\
\hline
\end{tabular}

Fuente: D.G.M. Elaboración propia.

Por último, resulta interesante comparar la composición por Rama de Actividad de los trabajadores extranjeros irregulares y la de los que se inscribieron al Censo (cf. cuadro 14). Ambos grupos se adscriben mayoritariamente al sector "Otros Servicios". El Censo no pormenoriza subsectores dentro de esta rama, por lo que no pueden establecerse comparaciones a 


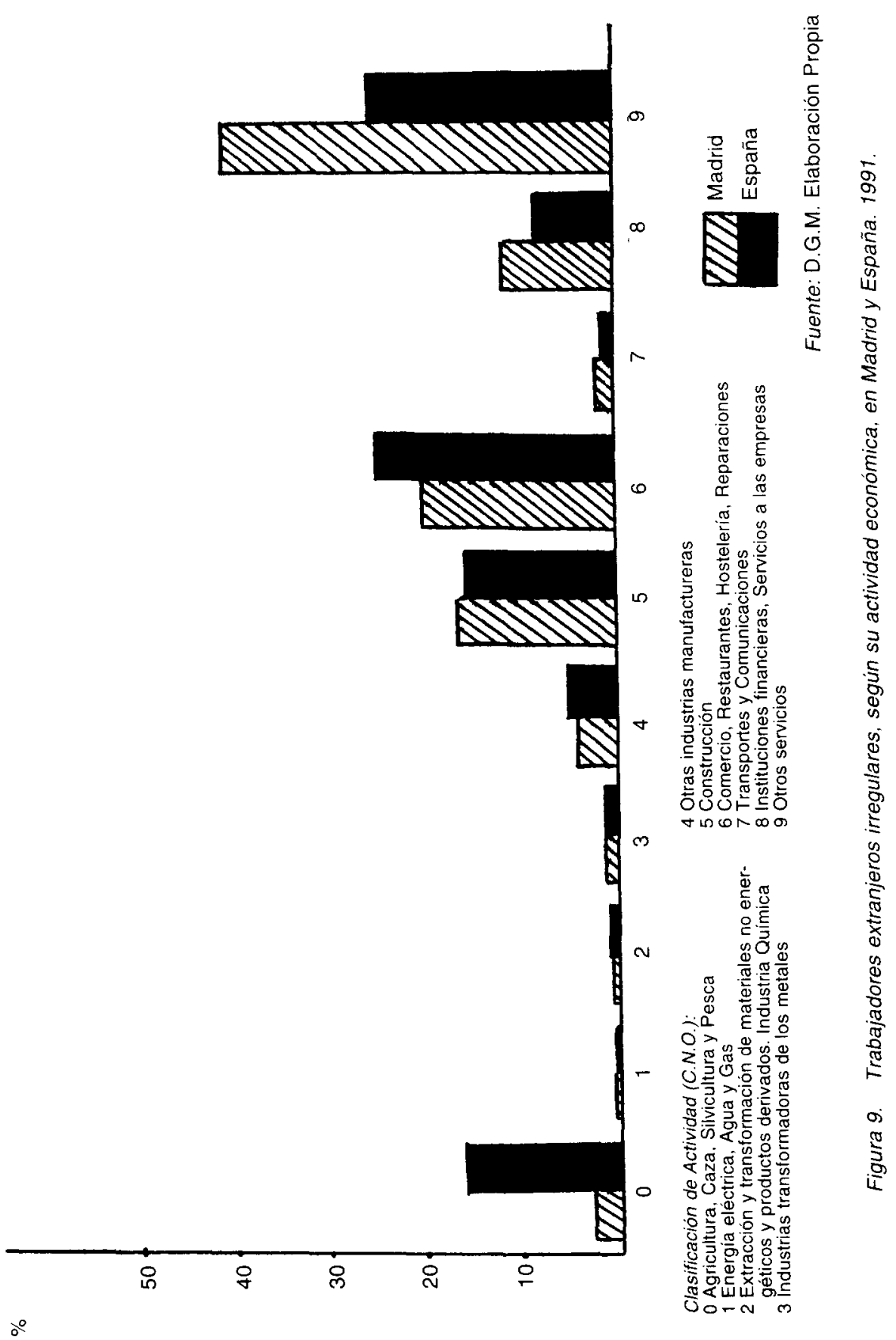


nivel más profundo; sin embargo, parece bastante claro que el epígrafe "servicio doméstico" estaría más representado entre los irregulares que entre los censados. La diferencia más notable entre un grupo y otro de trabajadores es la mayor importancia del sector construcción en los irregulares, mientras entre los censados es más relevante el sector industrial, sobre todo el de las industrias manufactureras.

CUADRO 14. TRABAJADORES EXTRANJEROS IRREGULARES Y CENSADOS EN MADRID, SEGUN RAMA DE ACTIVIDAD, 1991.

\begin{tabular}{|c|c|c|c|c|}
\hline & \multicolumn{2}{|c|}{ IRREGULARES } & \multicolumn{2}{|c|}{ CENSADOS } \\
\hline & C.A. & $\%$ & C.A. & $\%$ \\
\hline $\begin{array}{l}\text { Agricultura y Pesca ........ } \\
\text { Industrias extractivas y } \\
\text { manufact., Energía, Gas }\end{array}$ & 1.071 & 2,7 & 379 & 1,6 \\
\hline 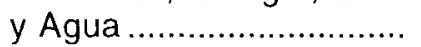 & 2.373 & 6,0 & 3.883 & 16,9 \\
\hline Construcción ................... & 6.521 & 16,5 & 1.758 & 7,6 \\
\hline Comercio & 7.930 & 20,1 & 4.467 & 19,3 \\
\hline 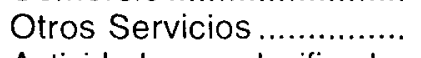 & 21.273 & 53,9 & 12.629 & 54,6 \\
\hline $\begin{array}{l}\text { Actividades no clasificadas } \\
\text { y N.C. }\end{array}$ & 316 & 0,8 & - & - \\
\hline TOTAL & 39.484 & 100,0 & 23.116 & 100,0 \\
\hline
\end{tabular}

Fuente: D.G.M. e I.N.E. Elaboración propia

En conclusión, tanto en lo que se refiere a la ocupación como en lo relativo a la rama de actividad económica, los trabajadores extranjeros en situación irregular están fuertemente asociados a los servicios domésticos en Madrid. En el caso de las mujeres, esta adscripción es mayoritaria. En el caso de los hombres, se combina con otras actividades como la construcción y, en menor medida, el comercio y la industria.

\section{DISTRIBUCIÓN ESPACIAL DE LOS EXTRANJEROS IRREGULARES EN LA COMUNIDAD DE MADRID}

Madrid capital, la aglomeración mas importante de la comunidad, centro de servicios y mercado de trabajo, ejerce una fuerte atracción sobre la población extranjera: en torno al $60 \%$ de los irregulares residen en el municipio; la misma proporción que entre los extranjeros que se inscribieron en el último Censo de población. Un peso, por otra parte, que coincide con el de la población del conjunto de la comunidad que reside en la capital (cf. cuadro 15). 


\section{CUADRO 15. DISTRIBUCIÓN ESPACIAL DE LOS EXTRANJEROS IRREGULARES Y CENSADOS EN LA C.A.M. COMPARACIÓN CON LA POBLACIÓN AUTÓCTONA, 1991.}

\begin{tabular}{|c|c|c|c|c|c|}
\hline & \multicolumn{2}{|c|}{$\begin{array}{l}\text { EXTRANJEROS } \\
\text { IRREGULARES }\end{array}$} & \multicolumn{2}{|c|}{$\begin{array}{l}\text { EXTRANJEROS } \\
\text { CENSADOS }\end{array}$} & \multirow{2}{*}{$\begin{array}{c}\text { POBLACIÓN } \\
\text { C.A.M. } \\
\%\end{array}$} \\
\hline & C.A. & $\%$ & C.A. & $\%$ & \\
\hline Madrid Capital ..... & 24.068 & 61,0 & 36.913 & 61,4 & 60,8 \\
\hline A. Metrop. Norte... & 1.381 & 3,5 & 5.475 & 9,1 & 3,5 \\
\hline A. Metrop. Este..... & 2.047 & 5,2 & 3.487 & 5,8 & 7,6 \\
\hline A. Metrop. Sur .............. & 4.565 & 11,6 & 5.973 & 9,9 & 17,8 \\
\hline A. Metrop. Oeste ............. & 2.353 & 5,9 & 4.291 & 7,1 & 3,1 \\
\hline Resto C.A.M. ...................... & 5.070 & 12,8 & 4.024 & 6,7 & 7,2 \\
\hline 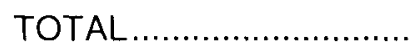 & 38.484 & 100,0 & 60.163 & 100,0 & 100,0 \\
\hline
\end{tabular}

Fuente: D.G.M.y C.A.M. Elaboración propia.

La corona metropolitana, en torno a ella, es el segundo espacio de asentamiento, tanto para la población autóctona, como para los extranjeros censados - un tercio de los efectivos en ambos casos- y, secundariamente, aunque en menor medida, también para los irregulares. Fuera de la gran metrópoli madrileña, el volumen de población residiendo en el "resto de la C.A.M." es muy reducido, tanto en lo que se refiere a los propios madrileños como a los extranjeros, si bien se aprecia un mayor peso de los irregulares en este espacio.

En comparación con la población autóctona, destaca en la distribución de los extranjeros que se inscribieron en el Censo el reducido peso de los que residen en la corona metropolitana Sur -zona industrial y de residencia obrera - y la mayor concentración en las áreas Norte y Occidental de la corona metropolitana, áreas de expansión residencial de medio y alto status. Los irregulares, por su parte, muestran una mayor atracción por los municipios de la corona metropolitana Sur -aunque su peso en ella es inferior al de la población autóctona- y, sobre todo, como se dijo anteriormente, por los municipios de fuera del área metropolitana.

A nivel municipal, la distribución espacial de los extranjeros irregulares y censados es muy parecida (cf. fig. 10), con un claro dominio de la capital sobre el resto del territorio y una representación de los municipios próximos a ella, sobre todo del área occidental y hacia la Sierra de Guadarrama, la "sierra rica", donde pueblos como Collado Villalba, Galapagar o Valdemorillo tienen una mayor relevancia entre los irregulares que entre los censados. En el extremo opuesto, otra zona de asentamiento 


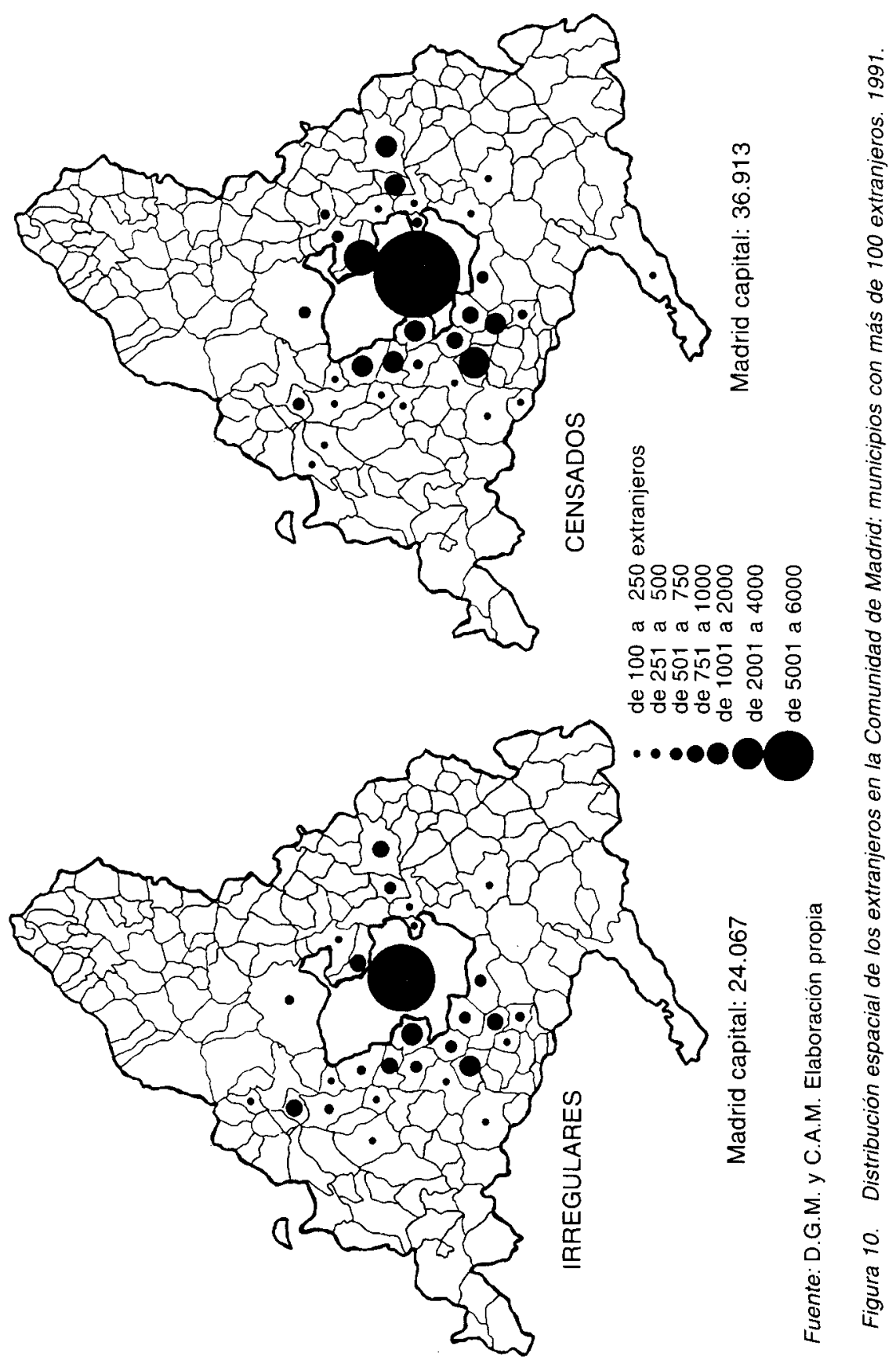


fundamental es el corredor del Henares -Coslada, San Fernando, Torrejón de Ardoz y Alcalá de Henares-, zona de atracción, sobre todo, de la colonia estadounidense, por su relación con la base militar de Torrejón y, por tanto, más destacada entre los censados - recordemos que esta colonia es la más importante numéricamente entre los extranjeros inscritos en el Censo.

El peso de los extranjeros dentro de la población de cada municipio (cf. fig. 11) señala los valores máximos en el área occidental de la comunidad, fuera de la capital, comprendiendo la corona metropolitana occidental y municipios de la "sierra rica", formando un arco que asciende hasta las estribaciones de la "sierra pobre". En el caso de los irregulares, se dan valores muy elevados en algunos municipios poco poblados, donde un reducido numero de ellos eleva las cifras porcentuales de forma importante: tal es el caso de Navalagamella, donde los 91 extranjeros irregulares registrados suponen el $14,6 \%$ de la población del municipio, y, secundariamente, Fresnedillas, Valdemorillo, Villanueva del Pardillo y Becerril, que con menos de 200 irregulares en todos los casos, tienen un peso de en torno al $6 \%$ de la población total de cada municipio. También Villanueva del Pardillo y su vecino Villanueva de la Cañada tienen un peso importante de extranjeros censados, así como, en el extremo opuesto, Alcobendas, que es el municipio fuera de Madrid de mayor concentración de extranjeros entre los censados (4.282), fundamentalmente norteamericanos.

Los irregulares muestran, pues, una atracción clara por los municipios del área occidental de la Comunidad de Madrid, zona de expansión de las clases medias y acomodadas. Aqui figuran algunos pueblos con un volumen importante de extranjeros en situación irregular: Pozuelo de Alarcón, con 1.072, Majadahonda, con 889, Boadilla del Monte, con 504, Las Rozas, con 463 y, mas distantes, Collado Villalba, con 869 irregulares, Galapagar, con 272 y Villaviciosa de Odón, con 216. Fuera de esta zona, destaca el área metropolitana Sur, como sabemos, donde se alcanzan cifras elevadas en algunos municipios, como Móstoles - 1.313 irregulares-, Fuenlabrada -855-, Leganés -666-, Alcorcón -611-, Getafe 559- y Parla - 469. El resto de la corona metropolitana muestra como valores absolutos más relevantes, Alcobendas - 876 irregulares-, Alcalá de Henares -872- y Torrejón de Ardoz -746-, a distancia de Colmenar Viejo y San Sebastián de los Reyes, con 295 y 210 irregulares respectivamente.

Como cabía esperar, se observan diferencias en las pautas de asentamiento de los extranjeros, a nivel de continente de nacionalidad y, dentro de ello, entre irregulares y censados. La atracción por Madrid capital 


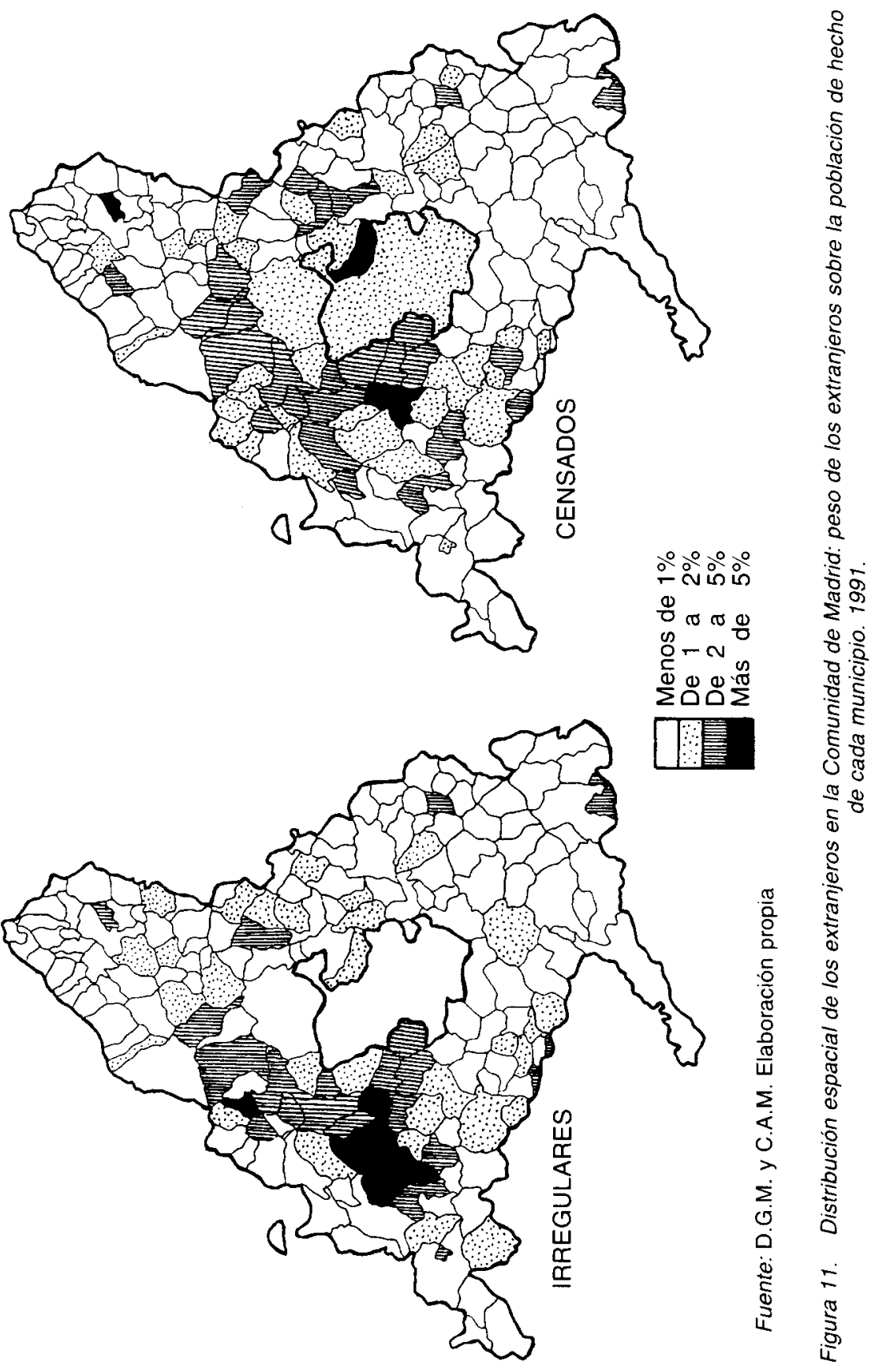


(cf. fig. 12) es clara en todos los grupos, si bien la menor se produce entre los norteamericanos censados - ya se comentó en otro lugar su preferencia por municipios como Alcobendas, Alcalá de Henares o el propio Torrejón de Ardoz, por su relación con la base militar- y los irregulares procedentes del "resto de Europa", polacos en su mayoría, que adoptan una distribución espacial particular, como veremos más adelante. Los altos porcentajes de norteamericanos y nacionales de Oceanía en situación irregular residiendo en Madrid capital que refleja el gráfico, tienen escasa significación estadística, debido al reducido número de individuos que componen ambos grupos.

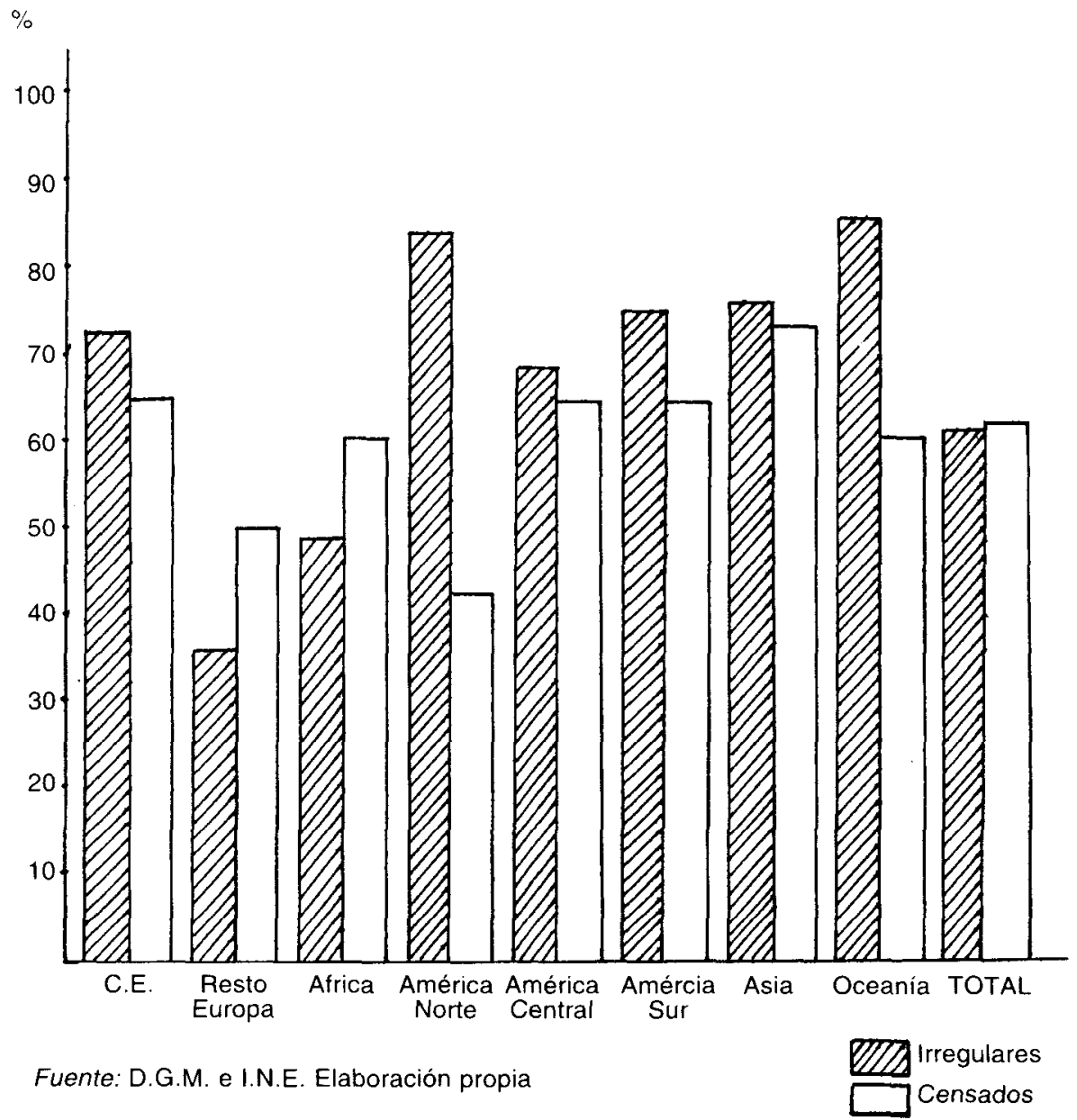

Figura 12. Extranjeros irregulares y censados en Madrid capital. Proporción sobre el total de cada colonia. 1991. 
En general, puede decirse que asiáticos, sudamericanos y comunitarios alcanzan las mayores proporciones de sus efectivos residiendo en la capital, mientras norteamericanos, europeos extracomunitarios y africanos muestran las menores. La diferencia de valores entre censados e irregulares, fuera de los grupos sin valor estadístico antes señalados, es mayor en los nacionales del resto de Europa, los sudamericanos y los africanos. En los dos primeros casos, la diferencia en los paises más representados puede ser la causa: ya se observó con anterioridad cómo entre los censados del resto de Europa están representados sobre todo los nacionales de "paises ricos", mientras entre los irregulares son los polacos y otros nacionales de paises del Este los que tienen más peso; en lo que se refiere a los sudamericanos, entre los censados son los argentinos y venezolanos los mas representados, mientras entre los irregulares figuran otras nacionalidades en cabeza - Perú, Colombia, Chile...-, además de Argentina. En cuanto a los africanos, mayoritariamente marroquies en ambos casos, la diferencia puede deberse a una tendencia más reciente a la dispersión - quizá paralela a la diversificación en las áreas de origen- o a la expansión fuera de Madrid capital, debida a distintas razones, entre las que podría señalarse la conexión del grupo con la población acomodada, por motivos laborales, y la tendencia de esta última a salir del municipio de Madrid en los últimos años, así como el trabajo relacionado con las tareas agrícolas, ganaderas y forestales de parte de los irregulares, unido a los precios de los alojamientos, más asequibles cuanto mas distantes de la capital.

Ciñéndonos a la población extranjera en situación irregular, las pautas de asentamiento son diferentes en los distintos grupos extranjeros a nivel de continente de nacionalidad (cf. fig. 13). Dejando a un lado a los nacionales comunitarios, norteamericanos y de Oceanía, cuyo reducido volumen $-1.109,796$ y 35 personas, respectivamente-, hace desaconsejable deducir conclusiones sobre su distribución, los restantes grupos muestran diferencias dignas de destacarse:

Los nacionales del resto de Europa son los que presentan una menor atracción por el municipio de Madrid: un 36\% escaso reside en él, adquiriendo, en cambio, un peso relevante el área metropolitana Sur $(29 \%)$ y Este $(21 \%)$ y estando prácticamente ausentes de las restantes áreas de la corona metropolitana. Es clara la relación entre la distribución espacial metropolitana-industrial de los nacionales del resto de Europa - procedentes mayoritariamente de paises del Este, singularmente Polonia- y la polarización laboral del grupo hacia actividades industriales, como se analizó en otro apartado. 

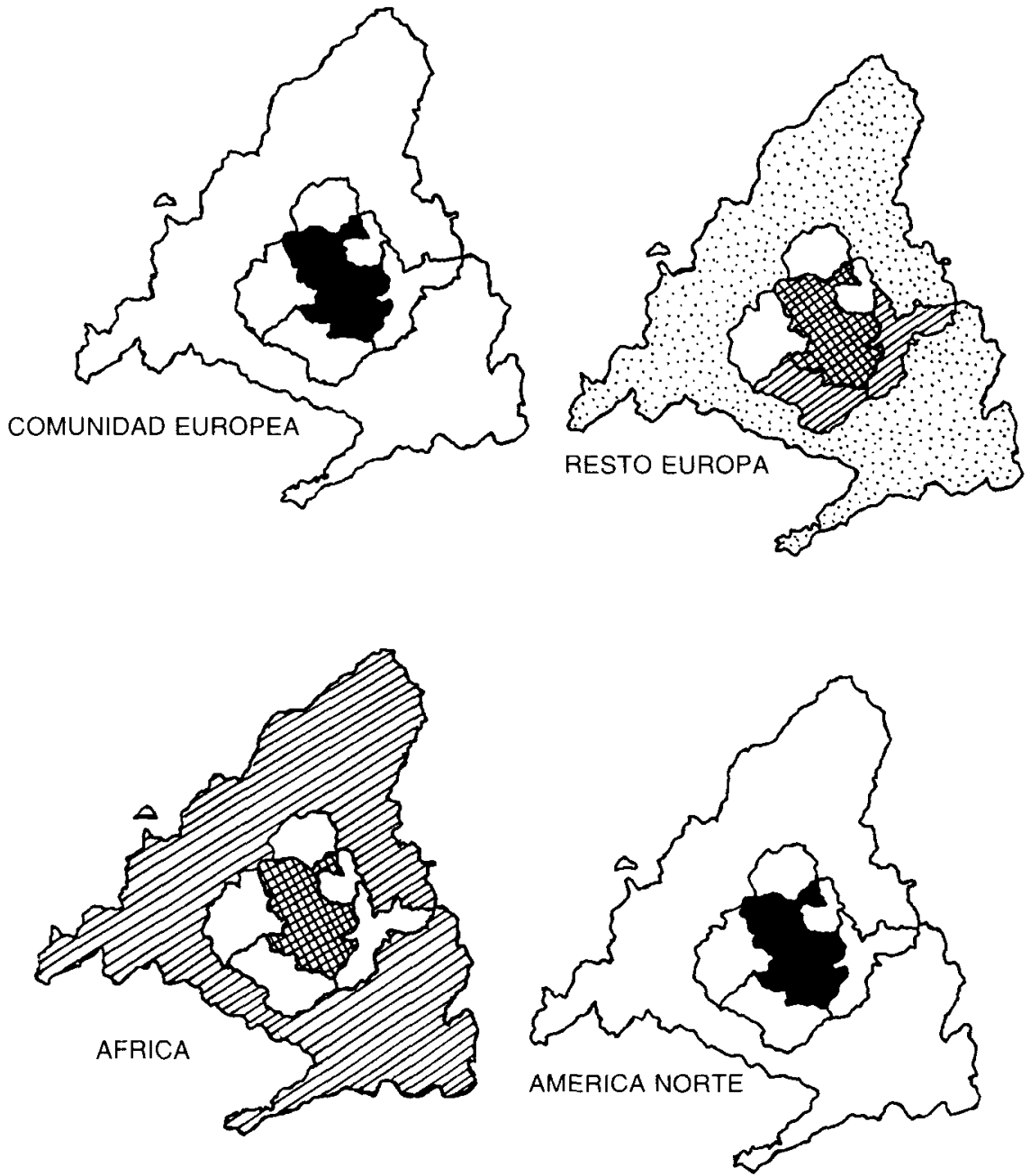

\begin{tabular}{|lrr} 
Menos & de & $8 \%$ \\
De $8 \%$ & a & $15 \%$ \\
De $15 \%$ & a & $30 \%$ \\
De $30 \%$ & a & $50 \%$ \\
De $50 \%$ & a & $75 \%$ \\
Más & de & $75 \%$
\end{tabular}

Fuente: D.G.M. Elaboración propia

Figura 13. a) Distribución espacial de los extranjeros irregulares en la Comunidad de Madrid, por continente de nacionalidad y áreas geográficas. 1991. 

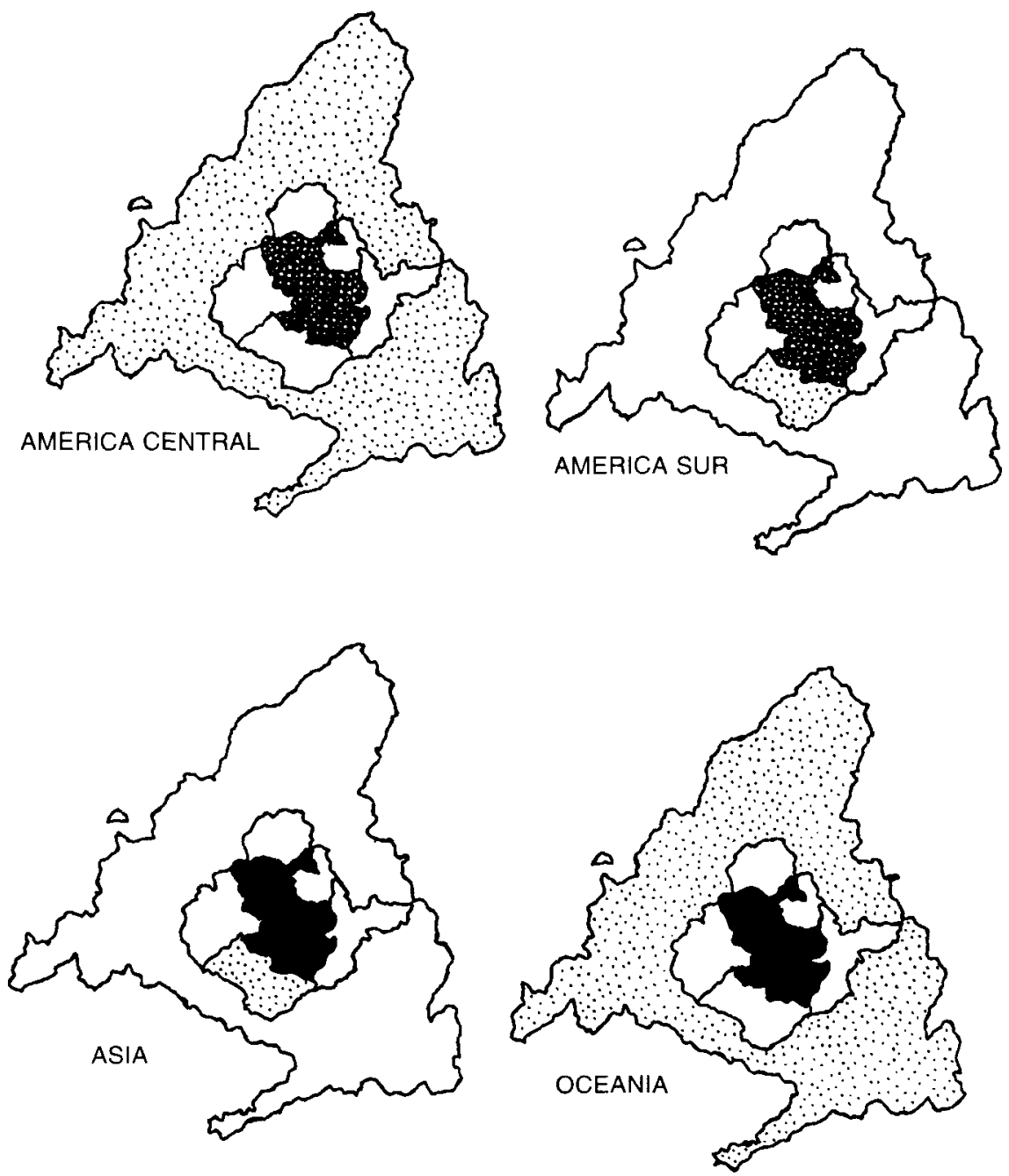

\begin{tabular}{|c|c|c|}
\hline & Menos & de \\
\hline$\because$ & De $\quad 8 \%$ & a \\
\hline QIII & De $15 \%$ & a \\
\hline 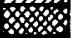 & De $30 \%$ & a \\
\hline & De $50 \%$ & a \\
\hline & Más & de \\
\hline
\end{tabular}

Fuente: D.G.M. Elaboración propia

Figura 13. b) Distribución espacial de los extranjeros irregulares en la Comunidad de Madrid, por continente de nacionalidad y áreas geográficas. 1991. 
La africana es la segunda colonia irregular que muestra una distribución descentralizada, si bien la capital reúne al $49 \%$ del grupo; un $23 \%$ se localiza en el "resto de la comunidad", un $12 \%$ en el área metropolitana Sur y un $9 \%$ en el área metropolitana Oeste. Sobre todo, en lo que se refiere a la localización fuera del marco del área metropolitana, se da un contraste entre irregulares y censados: estos últimos no cuentan más que con un $11 \%$ de efectivos fuera del ámbito de la metrópoli. En conjunto, casi un tercio de los africanos irregulares -fundamentalmente marroquíes - se localiza al Oeste de la capital, en los municipios de la corona metropolitana y la "sierra rica". La diversidad ocupacional de la colonia determina en gran parte esta localización: se trata de un área en expansión, donde crecen las urbanizaciones y zonas residenciales para las clases medias y acomodadas y donde las ocupaciones relacionadas con la agricultura, ganadería y bosques, por un lado, y la jardineria, construcción y servicio doméstico, por otro, tienen un amplio desarrollo.

Las restantes comunidades muestran una distribución más concentrada en Madrid capital, superando esta localización dos tercios de los efectivos de cada colonia, en todos los casos. La dedicación preferente a los servicios en todas ellas, es la que de alguna manera determina la fuerte atracción de Madrid capital. En algunas colonias, por último, destaca la zona Sur metropolitana como lugar secundario de asentamiento, en función, por una parte, del trabajo en la industria de algunos de sus integrantes, y, por otra, debido al precio más asequible de las viviendas en ella.

En conclusión, en lo que se refiere a la distribución espacial de los extranjeros en situación irregular, Madrid capital es el foco receptor más importante de la comunidad en todos los casos. En contraste con otras metrópolis de acogida de inmigrantes, los extranjeros en Madrid no se localizan en las áreas industriales y obreras, más que en una pequeña proporción. Debido a su estrecha relación con las ocupaciones de servicios, los inmigrantes madrileños tienden a localizarse en la aglomeración central, en las áreas de expansión y en las de segunda residencia, por su variada oferta laboral.En todo caso, siguen, sobre todo, las pautas de asentamiento de las clases medias y altas, que son las que mayoritariamente les emplean.

\section{CONCLUSIÓN}

Tras la Regularización, los «ilegales", han venido a incrementar las cifras oficiales de residentes $y$, sobre todo, las de extranjeros con permiso 
de trabajo en la C.A.M., a pesar de que no todos los trabajadores irregulares aquí considerados accedieron a la legalidad: como sabemos, 3.747 personas no consiguieron el permiso solicitado, permaneciendo en situación irregular.

Los permisos concedidos habian de ser renovados anualmente. La dificultad en muchos casos para reunir los requisitos para la renovación, motivó que un cierto número de los regularizados volviera a la ilegalidad en años sucesivos. Estos, unidos a los que no consiguieron los permisos en la operación, los que no se presentaron a ella y todos aquellos que con posterioridad a la misma han ido entrando de forma clandestina, configuran la nueva "bolsa de irregularidad" con que cuenta Madrid en la actualidad, cuya dimensión nos es desconocida. El fenómeno de la irregularidad continúa vigente.

Ello hace que, desde el punto de vista de la investigación del fenómeno inmigratorio, el análisis del Fichero de Regularización, que contiene un volumen próximo a 40.000 casos de ciudadanos extranjeros en situación irregular en la C.A.M., tenga un gran valor para el conocimiento de las características de este grupo de población que vive entre nosotros. A pesar del desfase -la fecha de referencia es mayo del 91-, el perfil del grupo, deducido de las características de sus componentes, tiene total actualidad.

La fuente analizada aquí es, pues, de una importancia capital, aunque no investiga algunas variables de interés, como, por ejemplo, la fecha de llegada, el nivel de instrucción, el tipo de vivienda o la distribución espacial, entre otras posibles.

La fecha de llegada es fundamental, no sólo en el estudio diacrónico de la corriente inmigratoria, sino también para conocer en qué medida está afectando la ley de extranjería y su reglamento de aplicación en la relegación a la ilegalidad de ciudadanos extranjeros de antigua presencia entre nosotros. El nivel de instrucción es una variable de interés singular en el estudio del status socioeconómico de la población, lo mismo que el tipo de vivienda; ambas son caracteristicas de gran valor a la hora de trazar el perfil de las diferentes colonias que configuran el colectivo inmigrante irregular. En cuanto a la distribución espacial, en principio estaba contemplada en las fichas de inscripción; sin embargo, no se informatizó más que el municipio de residencia y en un campo literal, como se ha señalado en otro momento. En nuestro caso este problema se subsanó realizando una codificación de este campo sobre el Fichero; sin embargo, la distribución de la población en el interior del municipio de Madrid no pudo analizarse por no hallarse la variable en él.

Aún otras características de este colectivo - modo de entrada, familiares dependientes, proyecto inmigratorio, ingresos, ocupación en el país 
de origen, etc.- habrian sido de gran interés y de hecho algunas de ellas fueron tratadas en la encuesta realizada por la D.G.M. a una muestra de la población regularizada. Sin embargo, no contamos con los datos a nivel de colonias, ni conocemos la fiabilidad de la muestra.

Con todo, no se debe subestimar la información que poseemos, que es de enorme valor. A través de ella, y a pesar de que en estas páginas, por falta de espacio, no se realiza más que un análisis superficial sin pretensión de profundizar en cada colonia, se pueden extraer una serie de conclusiones sobre el colectivo extranjero en situación irregular en Madrid:

La irregularidad se da, sobre todo y como ya sabiamos, entre ciudadanos de áreas y paises concretos, fundamentalmente paises subdesarrollados y en vías de desarrollo. Aunque los hay, son pocos los irregulares procedentes de paises desarrollados, en contraposición con los que acudieron a la Regularización de 1985-86, cuyas características fueron estudiadas por A.Izquierdo (1991 y otras publicaciones) y que en mayor medida procedian de Europa Occidental. En Madrid, por otra parte, la presencia africana es menos relevante que en España entre los irregulares, si bien la primacía de Marruecos queda patente. Nuestra comunidad se caracteriza por ser foco importante de atracción de ciudadanos latinoamericanos, tanto irregulares, como regulares. Por otra parte, colonias recientes en España, como la polaca o la dominicana, tienen en ella la máxima representación.

El perfil claramente masculino, joven y soltero, de los irregulares en España se repite en Madrid, si bien en la comunidad que nos ocupa el carácter de los irregulares es notablemente más "femenino" que en España y ello por dos motivos fundamentales: por la mayor presencia de colonias claramente femeninas - como la filipina o, sobre todo, la dominicana- o con un equilibrio entre los sexos - como muchas de las latinoamericanas-y, causa y efecto de ese primer factor, por la importante oferta de empleo que se produce en la comunidad en el sector del servicio doméstico, ocupación de carácter marcadamente femenino, en la que trabajan dos tercios de las mujeres irregulares presentes en Madrid.

En comparación con la población activa ocupada que se inscribió en el último Censo de población - sincrónico a la fecha de referencia de la Regularización- y que consideramos en su mayoría regulares o legales, los trabajadores irregulares en Madrid son notablemente más jóvenes, son en mayor medida varones y tienen ocupaciones de menor cualificación, sobre todo en los sectores de la construcción y los servicios - hostelería y servicio doméstico fundamentalmente. En relación con los irregulares del conjunto de España, la representación de los trabajadores en la agricultura y ganadería es mucho menor en Madrid. 
Una de las caracteristicas de los extranjeros en situación irregular en la comunidad que nos ocupa es su escasa polarización ocupacional hacia actividades industriales. En este sentido, contrastan con otros grupos inmigrantes en otras ciudades europeas, que tradicionalmente engrosan el peonaje industrial. La industria en Madrid ocupa sobre todo a trabajadores autóctonos, siendo el sector servicios, más fácilmente "sumergible", el disponible para los trabajadores extranjeros en situación irregular. La construcción es el segundo sector de signiticativa ocupación entre ellos.

La distribución espacial de los irregulares es parecida a la de los extranjeros censados, si bien con una menor presencia en el área metropolitana norte y oeste - de más elevado status socioeconómico- y mayor fuera de la metrópoli. La atracción del municipio de Madrid, tan fuerte como entre la población autóctona y entre los extranjeros censados, es una característica fundamental. Otra es la importante atracción del área occidental de la comunidad, sobre todo de los municipios próximos a la capital que han protagonizado un mayor crecimiento y expansión en los últimos años, como Pozuelo, Majadahonda, Las Rozas o Boadilla del Monte, y los de la "Sierra Rica". Dentro de ello, se observan pautas de asentamiento diferenciales en las distintas colonias, siendo la marroquí la que ofrece una mayor atracción hacia ese área concreta y la polaca la que muestra una menor polarización hacia el municipio de Madrid y mayor hacia los sectores oriental y meridional del área metropolitana. En conjunto, la distribución espacial es en gran medida reflejo de las ocupaciones preferentes de los distintos grupos. La escasa dedicación a la industria, por ejemplo, incide en el reducido papel de la corona metropolitana sur como espacio de asentamiento entre los irregulares, en relación con su peso en el conjunto de la población autóctona; este espacio tiene relevancia, sobre todo, en colonias concretas, como la polaca y algunas negroafricanas. Otras colonias dedicadas preferentemente al sector servicios siguen en su localización las pautas de la población autóctona, sobre todo la más acomodada.

Por último, en lo que se refiere al carácter más o menos familiar de la inmigración irregular en Madrid, no se pueden establecer conclusiones rigurosas a la luz de los datos con que contamos. Parece claro que se trata de una inmigración de carácter menos familiar que la asentada: la elevada proporción de personas solteras, la edad joven del colectivo y el reducido numero de familiares que acudió a la operación paralela de Regularización de Familiares, parecen indicarlo. El carácter eminentemente laboral de la Regularización desaconseja el estudio de las características familiares del colectivo. La evidencia, por otra parte, de un subregistro de familiares en las estadísticas del proceso paralelo antes mencionado, por la insuficiente difusión, el reducido plazo y la limitación del mismo a los familiares de los 
trabajadores recién regularizados, resta toda fiabilidad a la única fuente disponible para el estudio de esta variable.

\section{FUENTES Y BIBLIOGRAFIA}

ARAgón. R. y ChOzAS, J. (1993): "La Regularización de inmigrantes durante 1991-1992". Ministerio de Trabajo y Seguridad Social. Serie Informes y Estudios.

Bodega, M.I., Cebrián, J.I., Franchini, M.T., Lora-Tamayo, G. y Martín lou, M.A. (1992): "Inmigración marroqui en la CAM". Anales de Geografía de la Universidad Complutense no 12, pags 291-311.

Boletin Oficial de las Cortes Generales, serie D, n 165, 22 de Marzo de 1991.

CAM (1993): "Situación económica y social de la Comunidad de Madrid 1992". Consejo Económico y Social.

CAM (1993): "Censos de Población y Viviendas de 1991. Tomo 1: Características demográficas básicas y fecundidad de la población". Consejería de Economia.

CERÓN RIPOLL, P. (1995): “Inmigrantes dominicanas: camino hacia la reagrupación familiar". Actas del $\vee$ Congreso de la Población Española, pags. 35-42. Barcelona.

COLECTIVO IOÉ (1987): “Los inmigrantes en España". Documentación Social n 66. Enero-Marzo.

COLECTIVO IOÉ (1993): “Rasgos generales y pertil sociodemográfico de las principales colonias", en C. GIMÉNEZ ROMERO (Coord) (1993): “Inmigrantes extranjeros en Madrid" Tomo 1, pp. 137-418.

Comunicación del Gobierno al Congreso De los Diputados (1990): "Situación de los Extranjeros en España. Líneas básicas de la politica española de extranjeria".

DIARIO EL SOL, 13 de marzo de 1991.

Dirección General de Migraciones (1992): "Anuario de Migraciones 1992". M de Trabajo y Seguridad Social.

Dirección General de Migraciones (1993): "Anuario de Migraciones 1993". M de Trabajo y Seguridad Social.

Dirección General de Migraciones (1993): "Informe Estadístico de Regularización hasta el 30 de noviembre de 1993". Ministerio de Asuntos Sociales.

DiRECCIÓn GeneRAL DE Migraciones (1993): “informe Estadistico de Regularización hasta el 31 de diciembre de 1993". Ministerio de asuntos Sociales.

Dirección General de Migraciones (1993): "Fichero de Regularización del proceso inicial por domicilio y de ámbito nacional. Madrid". Actualización: 1 de diciembre de 1993. Soporte magnético.

Difección General de Migraciones (1993): "Anuario de Migraciones 1993". M de Trabajo y Seguridad Social.

DIRECCIÓN GENERAL DE POLICIA (1993): “Regularización de familiares de trabajadores extranjeros" Comisaría de Documentación. (Información solicitada).

Giménez Romero, C. (1992): "Madrid y el desafío de la inmigración. Conclusiones del proyecto de investigación "Dimensionamiento y análisis por grupos étnicos de la población inmigrante del Tercer Mundo y Portugal en la Comunidad Autónoma de Madrid". Mayo 1992.

Giménez Romero, C. (1993) (Coord): cinmigrantes extranjeros en Madrid". 2 tomos, CAM. Serie Informes Técnicos, $n^{\circ} 4$.

González Yancí, M.P., Aguilera Arilla, M.J. y Rodriguez Rodríguez, V. (1992): “Estudio de la ocupación, caracteristicas, localización y alojamiento de los inmigrantes extranjeros en Madrid y Corona Metropolitana". Informe I.E.E.

HeRranz Gómez, Y. (1993): "Latinoamericanos en Madrid: Integración en la sociedad española». Revista Española de Antropología Americana, 23. pp. 187-211. Edit. Complutense.

instituto Nacional de Estadistica (1992): «Censos de Población y Viviendas, 1991. Muestra Avance. Principales Resultados".

Instituto Nacional DE Estadistica (1994): "Censo de Población de 1991. Tomo I: Resultados Nacionales". Madrid.

Instituto Nacional de Estadística (1995): "Censo de Población de 1991. Tomo II. Resultados autonómicos y provinciales. Caracteristicas generales de la población. Comunidad de Madrid". Madrid. 
InSTITUTO NACIONAL dE Estadistica (1995): Tablas específicas de extranjeros correspondientes al Censo de Población de 1991, obtenidos del SAETA. Comunidad de Madrid.

IZQUiERDO ESCRIBANO, A. (1991): "La inmigración ilegal en España. Análisis de la operación extraordinaria de Regularización de 1985-86". Economia y Sociologia del Trabajo nº 11. Ministerio de Trabajo y Seguridad Social, pags 18-38.

LÓPEZ TrIGAL, L. (Dir.) (1994): "La migración de portugueses en España". Universidad de León.

LORA-TAMAYO D'OCÓN, G. (1991): "La inmigración extranjera a la Comunidad de Madrid en el contexto español». Terceras Jornadas sobre la población española. Diputación Provincial de Málaga, 1991, pags. 109-116.

LORA-TAMAYO D'OCÓN, G. (1993): “Inmigrantes extranjeros y vivienda marginal en Madrid". Espacio, Tiempo y Forma, Serie VI, n 6, pp. 153-167.

LORA-TAMAYO D'OCón, G. (1994): "Valor de la inmigración extranjera en España" Espacio. Tiempo y Forma, Serie VI, $n^{2} 7, p p .83-134$.

LORA-TAMAYO D'OCÓN, G. (1995, a): "Caracteristicas de la población extranjera en España. Censo de 1991 ". Cuadernos de Formación n 6, D.D.M.-ASTI.

Lora-Tamayo D'OCon, G. (1995, b): "Extranjeros en España en 1991". Estudios Geográficos (en prensa).

MINISTERIO DEL INTERIOR (1989): “Cuadros estadísticos de Regularizaciones 1985-86”. En “Memoria 1989", pags. 126-131.

PASS (1990): "Mapa de trabajadores extranjeros en situación irregular en España". Informe. Dirección General del I.E.E.

PeredA, C. (1987): "Los inmigrantes extranjeros en Madrid". Alfoz $n^{0} 44$, sept/87, pags 56-64.

PUMARES FERNÁNDEZ, P. (1993): "L'inmigration marocaine dans la communauté autonome de Madrid". Revue Européene des Migrations Internationals. Volume $9-\mathrm{n}^{9} 1,1993$.

Pumares Fernández, P. (1994): “La inmigración marroquí en la Comunidad de Madrid". 2 vols. Tesis Doctoral. Universidad Complutense de Madrid.

Rodriguez, V., Gonzalez YANCI, M.P., AGUILERA, M.J. (1992): "Los inmigrantes extranjeros en el espacio social madrileñon. Espacio, Tiempo y Forma, Serie VI, Tomo 5, pags. 91-106.

Mi agradecimiento a Román Garcia Oliver, Director General de Inmigración, quien desinteresadamente me facilitó la información correspondiente al proceso de Regularización de Trabajadores llevado a cabo en Madrid.

A Ignacio Estévez, Estadístico Técnico, mi reconocimiento por su eficaz labor en la codificación y puesta a punto del Fichero.

Gracias, asimismo, a Mari Carmen Pérez Delgado por su colaboración en la recogida de información de la prensa diaria y a Angeles LoraTamayo, por su aportación en todo lo referente a los datos estadísticos del Censo de población. 